\title{
Airborne measurements of aerosol optical properties related to early spring transport of mid-latitude sources into the Arctic
}

\author{
R. A. de Villiers ${ }^{1}$, G. Ancellet ${ }^{1}$, J. Pelon ${ }^{1}$, B. Quennehen ${ }^{2}$, A. Schwarzenboeck ${ }^{2}$, J. F. Gayet ${ }^{2}$, and K. S. Law ${ }^{1}$ \\ ${ }^{1}$ UPMC Univ. Paris 06; Université Versailles St-Quentin; CNRS/INSU, LATMOS-IPSL, France \\ ${ }^{2}$ Laboratoire de Météorologie Physique, Université B. Pascal, CNRS, France
}

Received: 1 December 2009 - Published in Atmos. Chem. Phys. Discuss.: 23 December 2009

Revised: 13 April 2010 - Accepted: 12 May 2010 - Published: 1 June 2010

\begin{abstract}
Airborne lidar and in-situ measurements of the aerosol properties were conducted between Svalbard Island and Scandinavia in April 2008. Evidence of aerosol transport from Europe and Asia is given. The analysis of the aerosol optical properties based on a multiwavelength lidar $(355,532,1064 \mathrm{~nm})$ including volume depolarization at $355 \mathrm{~nm}$ aims at distinguishing the role of the different aerosol sources (Siberian wild fires, Eastern Asia and European anthropogenic emissions). Combining, first aircraft measurements, second FLEXPART simulations with a calculation of the PBL air fraction originating from the three different mid-latitude source regions, and third level-2 CALIPSO data products (i.e. backscatter coefficient $532 \mathrm{~nm}$,volume depolarization and color ratio between 1064 and $532 \mathrm{~nm}$ in aerosol layers) along the transport pathways, appears a valuable approach to identify the role of the different aerosol sources even after a transport time larger than 4 days. Optical depth of the aerosol layers are always rather small $(<4 \%)$ while transported over the Arctic and ratio of the total attenuated backscatter (i.e. including molecular contribution) provide more stable result than conventional aerosol backscatter ratio. Above Asia, CALIPSO data indicate more depolarization (up to 15\%) and largest color ratio ( $>0.5$ ) for the northeastern Asia emissions (i.e. an expected mixture of Asian pollution and dust), while low depolarization together with smaller and quasi constant color ratio $(\approx 0.3)$ are observed for the Siberian biomass burning emissions. A similar difference is visible between two layers observed by the aircraft above Scandinavia. The analysis of the time evolution of the aerosol optical properties revealed by CALIPSO between Asia and Scandinavia shows a gradual decrease of
\end{abstract}

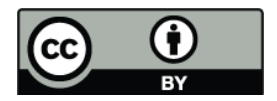

Correspondence to: $\mathrm{G}$. Ancellet (gerard.ancellet@upmc.fr) the aerosol backscatter, depolarization ratio and color ratio which suggests the removal of the largest particles in the accumulation mode. A similar study conducted for a European plume has shown aerosol optical properties intermediate between the two Asian sources with color ratio never exceeding 0.4 and moderate depolarization ratio being always less than $8 \%$, i.e. less aerosol from the accumulation mode.

\section{Introduction}

Radiative effects of aerosols can be quite different in the Arctic compared to elsewhere (Quinn et al., 2008). Weakly absorbing aerosol layers can be effective for heating the earth-atmosphere system considering the high surface albedo (Pueschel and Kinne, 1995). Frequent haze and cloud layers in the winter-spring period contributes also to surface heating by their infrared emission (Garrett and Zhao, 2006). Cloud formation processes are also very sensitive to the aerosol properties as Arctic clouds often contain low droplet concentrations. Shindell et al. (2008) have examined multi-model results to assess the aerosol and $\mathrm{CO}$ transport to the Arctic. They underline in their work the major role played by European and East Asian emissions especially in winter. There is also a very significant altitude dependence of the Arctic sensitivity to emission change. The relative influence of the different mid-latitude aerosol sources was already discussed by Rahn (1981) who concluded using meteorological considerations and observations about the relative importance of the Eurasian transport pathway. The review of Law and Stohl (2007) has also stressed the seasonal change of the air pollution transport into the Arctic with a faster winter circulation implying a stronger influence of the southerly sources.

Published by Copernicus Publications on behalf of the European Geosciences Union. 
Because of the strong low level winter transport barrier, these emissions are found in the middle and upper troposphere.

Two measurement campaigns in the Arctic took place during the spring season: TOPSE (Atlas et al., 2003) over the North American sector and ASTAR over the European sector (Engvall et al., 2008). Over the European Arctic sector, the ASTAR results have shown low level of aerosol particles even in layers with elevated $\mathrm{CO}$, suggesting aerosol removal in clouds. Occurrence of layers of non volatile and aged aerosol however increases with altitude in this region. The conditions during the ASTAR-2007 experiment were however exceptionally clean and other studies show events with large amount of polluted air masses in the lower troposphere, e.g. in spring 2006 (Stohl et al., 2007a).

Over the North American Arctic sector, little evidence was found for new particle formation (Weber et al., 2003) during TOPSE. The question of the relative influence on condensation nuclei of this low production rate and import from mid-latitudes could not be clearly assessed. Sulphate aerosol particles and more generally haze layers became more prevalent at higher altitudes across the winter to spring transition period during the TOPSE experiment (Scheuer et al., 2003). The aerosol lidar data during TOPSE (Browell et al., 2003) were mainly used to establish a link between the ozone and aerosol trends during the winter-spring transition, but some evidence was given of the role of the Eurasian sources on the observed aerosol optical properties.

Considering the crucial role of European and Asian emission suggested by the model studies and a significant altitude dependence of the occurrence of aerosol layers, new aircraft observations were conducted in 2008 at the same time over the European Arctic and North American sector to clarify questions raised during the previous campaigns (Jacob et al., 2009).

The purpose of this paper is to discuss how a backscatter lidar, in-situ aerosol and CO observations obtained over the European Arctic sector can be combined with a transport model and spaceborne measurements by the CALIOP lidar in order to get a better understanding of the aerosol source attribution in this region. This kind of methodology is also very useful for studying the aerosol evolution during the long range transport. Therefore, we focus on a given flight (11 April 2008), which is a very good example of the meteorological conditions encountered during the POLARCATFrance spring campaign. A short description of the POLARCAT (Polar Study using Aircraft, Remote Sensing, Surface Measurements and Models, of Climate, Chemistry, Aerosols, and Transport) campaign is given in Sect. 2. A more detailed description of the campaign achievements is planned in a forthcoming publication by Law et al. (2010). Our paper focuses on lidar data as they are especially useful to describe the vertical layering of the atmosphere and to derive the optical properties of the aerosol layers. We will analyze the complementarity of optical aerosol characterization and transport modeling studies for making source attribution of
Arctic tropospheric aerosol. A Lagrangian approach using aircraft observations and a model for the study of the long range transport is indeed a well established method for the analysis of observations at mid-latitudes (Fehsenfeld et al., 2006; Stohl et al., 2007b). But the main advantage of the POLARCAT campaign is to rely also on range resolved satellite observations by the CALIOP lidar providing aerosol layers optical properties at two different wavelength $(532 \mathrm{~nm}$, $1064 \mathrm{~nm}$ ). Our airborne lidar data must be analyzed using aerosol layer products similar to the CALIOP observations (Liu et al., 2009). This work also contributes to check how meaningful the CALIOP operational aerosol layer products are.

\section{Aircraft data and meteorological context}

\subsection{The POLARCAT spring campaign}

In 2008, two aircraft field campaigns have been successfully performed: the first one in Kiruna $\left(68^{\circ} \mathrm{N}, 20^{\circ} \mathrm{E}\right.$, North Sweden) in March-April and the second one in Kangerlussuaq (Greenland) in July. The ATR-42 was equipped with remote sensing instruments (lidar, radar), in-situ measurements of gas $\left(\mathrm{O}_{3}, \mathrm{CO}\right)$ and aerosols (Aerosol Mass Spectrometers, optical counters, size distribution). Cloud properties were analysed using a Counterflow Virtual Impactor (CVI). The flight strategy was often designed to collect data nearby satellite observations (Aqua-Train, Metop/IASI).

During the spring campaign the objectives were (i) characterization of the pollution transport, (ii) analysis of the aerosol/cloud interaction, (iii) satellite validation, and (iv) studies of the artic haze. The latter could not be addressed as sampling of the air masses North of the Arctic front was not possible with the limited range of the ATR-42. A set of 12 scientific flights was performed from 30 March to 11 April 2008 following more or less a South-North axis near $20^{\circ} \mathrm{E}$. A first contribution of POLARCAT was to combine aerosols and cloud droplets characterization to understand the aerosol/cloud interaction. The second major achievement was to identify numerous well defined aerosol layers in the free troposphere related to long range pollution transport. The third important result is the large number of flights conducted near the CALIPSO tracks. In the present paper, the second and third topics, will be addressed. Generally speaking this period was characterized by frequent northward transport of the European pollution and even the sampling of Asian pollution transported across the pole from 9 April to 11 April. To discuss the methodology developed in the paper, (i.e. a joint analysis of the aerosol airborne lidar data with CALIOP observations and FLEXPART modelling), we will focus on the results of 11 April 2008, because they include the two kinds of aerosol layers encountered during the POLARCAT spring campaign. 


\subsection{Flight description and meteorological context}

On April 11, 2008, the ATR-42 flew from Kiruna to the latitude circle at $73^{\circ} \mathrm{N}$. The purpose of this flight was to sample two kinds of air masses: one transported across the North Pole to Northern Scandinavia and the other one exported from Europe by mid-latitude weather systems. The Lagrangian FLEXPART model, used in a forecast mode (Stohl et al., 2004), indeed showed a well defined CO plume at $72^{\circ} \mathrm{N}$ and suggested long range transport of mid-latitude emissions. The meteorological situation can be described using the wind field at $700 \mathrm{hPa}$ and the vertical cross section of the specific humidity at $20^{\circ} \mathrm{E}$ along the flight pattern (Fig. 1). It shows that the aircraft measurements were collected between two frontal zones at $68^{\circ} \mathrm{N}$ and $74^{\circ} \mathrm{N}$. The wind field indicates a weak southerly flow in the southern part of the domain but then a well defined northerly flow at latitudes higher than $70^{\circ} \mathrm{N}$. Assuming advection along the isentropic surfaces in the free troposphere, the northerly flow also corresponds to a downward motion in the $3-6 \mathrm{~km}$ altitude range. We can also notice that, further east at $30^{\circ} \mathrm{E}$, the flow at northern latitudes remains southerly and intensifies. The corresponding flow curvature is related to the positive vorticity anomaly located at $25^{\circ} \mathrm{E}$ south of Spitzbergen. A flight in the latitude band $68^{\circ}-72^{\circ} \mathrm{N}$ is then interesting as its southern section characterizes an upward and northward flow corresponding to a fast and direct export from Europe, while its northern section samples the downward branch of the Arctic outflow with aged mid-latitude emissions according to the FLEXPART forecast. The red solid line in Fig. 1 corresponds to the aircraft vertical profile. During the first part of the flight between 10:00 UT and 11:30 UT, the aircraft flew above $3 \mathrm{~km}$ before a descent to explore the Arctic planetary boundary layer (PBL) at $72.5^{\circ} \mathrm{N}$. During the second part of the flight, i.e. the return to Kiruna, the aircraft stayed within the PBL for aerosol-cloud interaction studies and made a second exploration of the free troposphere for latitude below $70.5^{\circ} \mathrm{N}$. So, in addition to lidar data below the aircraft, four complete vertical profiles of the aerosol concentrations are derived from the in-situ measurements between 0 and $5.5 \mathrm{~km}$.

\subsection{Lidar measurements}

\subsubsection{Description of the lidar system}

The new version of the LEANDRE airborne backscatter lidar currently used for atmospheric dynamics studies (Flamant et al., 1996) and aerosol characterization (Pelon et al., 2002) is now providing measurements of total attenuated backscatter vertical profiles at three wavelengths $(355,532$ and $1064 \mathrm{~nm}$ ). The additional channel at $355 \mathrm{~nm}$ is now used to measure cross-polarization attenuated backscatter profiles. The main lidar characteristics are summarized in Table 1.

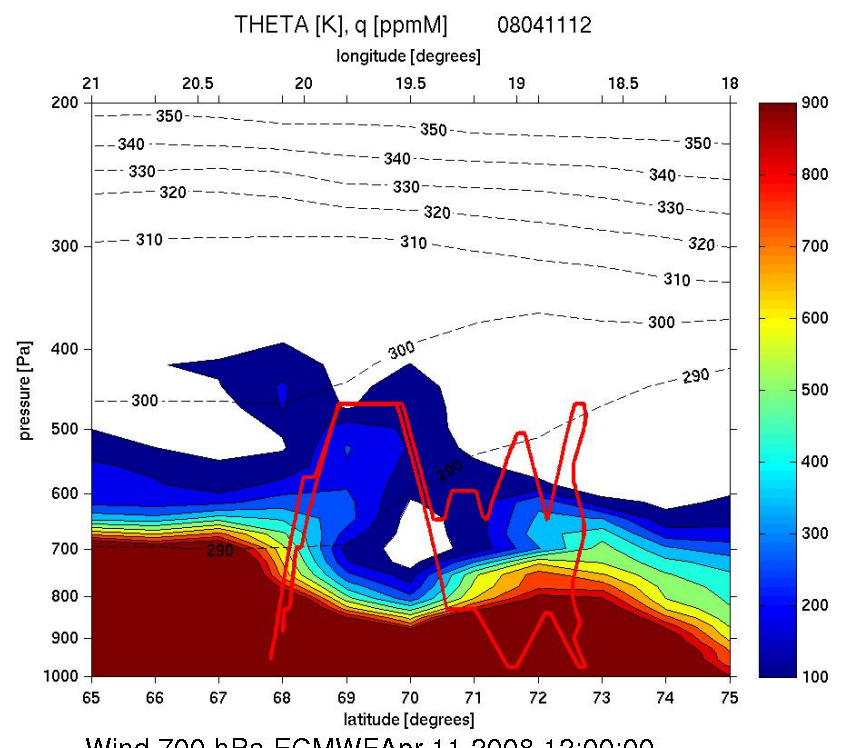

Wind $700 \mathrm{hPa}$ ECMWFApr.11,2008 12:00:00

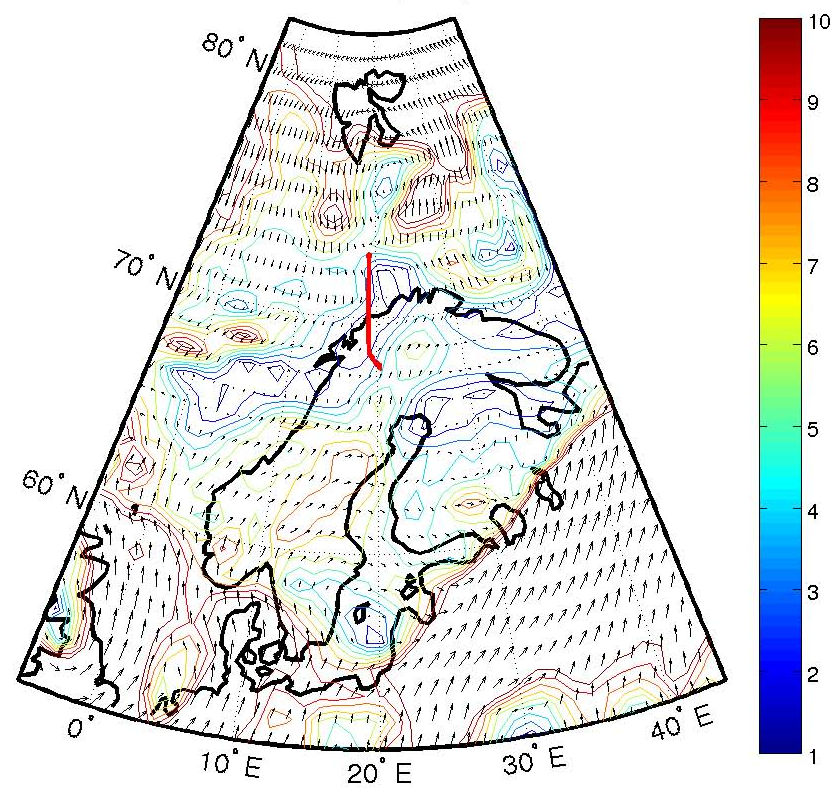

Fig. 1. Vertical cross section of ECMWF specific humidity showed by the color coded contour in ppmM, potential temperature in $\mathrm{K}$ showed by black dashed lines (top panel) and ECMWF wind field at $700 \mathrm{hPa}$ (bottom panel) on 11/04/2008 at 12:00 UT. The colored lines show the windspeed in $\mathrm{m} \mathrm{s}^{-1}$. The flight vertical and horizontal pattern are showed in red line.

The 355-nm pseudo depolarization ratio, $\delta_{355}$, i.e. the ratio of the the total perpendicular- to the total parallel-polarized backscatter coefficient (see Appendix A) is calculated in order to have a parameter comparable with the CALIOP volume depolarization ratio which is also based on the ratio of the total backscatter coefficient (Winker et al., 2009). The latter is however given at 532-nm and one must account for the spectral variation of this ratio from $355 \mathrm{~nm}$ to $532 \mathrm{~nm}$ 
Table 1. Airborne Lidar data characteristics.

\begin{tabular}{llll}
\hline Operation Wavelengths (nm) & 355 (Parallel and PP) & 532 & 1064 \\
Emitted energy (rep rate 20 Hz) & $50 \mathrm{~mJ}$ & $10 \mathrm{~mJ}$ & $80 \mathrm{~mJ}$ \\
Laser Divergence (FWHM) & $0.16 \mathrm{mrd}$ & $4 \mathrm{mrd}$ & $6.5 \mathrm{mrd}$ \\
Spot size @ 5 km & $0.8 \mathrm{~m}$ & $20 \mathrm{~m}$ & $33 \mathrm{~m}$ \\
Filter Width (FWHM) & $5 \mathrm{~nm}$ & $0.2 \mathrm{~nm}$ & $1 \mathrm{~nm}$ \\
Max. Filter Transmission (\%) & 25 & 25 & 30 \\
Telescope diameter & \multicolumn{3}{c}{$30 \mathrm{~cm}$} \\
Time Sampling and vertical resolution & \multicolumn{3}{c}{ 20 MHz or 7.5 m $(4$ points) } \\
Vertical resolution used & \multicolumn{3}{c}{ 4-5 (at ATR 42 cruise speed) } \\
Horizontal separation (shot-to-shot) & \multicolumn{3}{c}{ 450 (100 shots) } \\
Horizontal resolution used & \multicolumn{3}{c}{} \\
\hline
\end{tabular}

when comparing aircraft and satellite observations . For example, we can assume that the aerosol depolarization values weakly vary between 355 and $532 \mathrm{~nm}$ as explained in Appendix A (Freudenthaler et al., 2009; Sugimoto and Lee, 2006).

The pseudo depolarization ratio is calibrated on molecular scattering. From the values reported in Table 1, one can see that the interference filter width at $355 \mathrm{~nm}$ is much larger than the Cabannes line of the molecular backscattered signal and includes all Raman rotational lines due to nitrogen and oxygen which are the main scattering gases in the atmosphere (see Fig. 2 of Radlach et al. , 2008). Consequently, we will use the total Rayleigh+Raman depolarization value in clean air. We have adopted the value of $1.510^{-2}$ (Hostetler et al., 2006). Due to noise in normalization and possible biases, the error on the derived values is estimated to be $20 \%$.

For the same reason, i.e. a comparison with the CALIOP aerosol layer products, the pseudo color ratio which is the ratio of the 1064-nm to the 532-nm total backscatter coefficient, is calculated as it is a mean to identify aerosol type. Although this ratio is comparable to the CALIOP aerosol layer products (Winker et al., 2009), it will requires further correction for attenuation above the altitude of the aircraft as discussed later. The pseudo color ratio can be related to the aerosol color ratio more currently used for such a purpose (Cattrall et al., 2005). Details are given in Appendix A.

For the relative comparison between the aerosol layers properties seen by the airborne lidar and the comparison with the CALIOP observations, we will use the pseudo ratios. The main advantage of the pseudo ratios is to provide quasi-direct comparisons. As it accounts for molecular scattering, it leads to more stable values for weak aerosol layers and therefore relative comparisons are more robust. It however introduces a dependence with the scattering ratio (see Appendix A), which may in some cases lead to difficulties in interpretation. We thus have also given values of the standard parameters in the next sections for the strongest aerosol layers, which helps our analysis to be more comparable to previous studies.

\subsubsection{Aerosol lidar data on 11 April 2008}

A vertical cross section of the total attenuated backscatter in the infra-red (IR) channel is shown in Fig. 2. The areas with very large backscatter in the altitude range $1-2 \mathrm{~km}$ correspond to cloud layers developing at the top of the Planetary Boundary Layer (PBL). The cloud top reaches $3 \mathrm{~km}$ as the aircraft approaches the Arctic front. In the cloud free area, the layer from 0 to $1 \mathrm{~km}$ with larger aerosol backscatter values corresponds to the PBL. Well defined layers with enhanced aerosol backscatter are also detected in the free troposphere. The layer with a depth less than $1 \mathrm{~km}$ and with a meridian extent between $70^{\circ} \mathrm{N}$ and $72.5^{\circ} \mathrm{N}$ has the strongest relative signal compared to the background aerosol in the IR. This layer has also a slight vertical tilt, probably corresponding to the tilt of the isentropic surface. Another aerosol plume is also seen at latitudes less than $69.2^{\circ} \mathrm{N}$, but with a much larger altitude range between 3.5 and $5.5 \mathrm{~km}$ and weaker backscatter at $1064 \mathrm{~nm}$.

To further characterize these two layers, four 20-s averages of lidar profiles were analyzed: the first one corresponds to the thick layer at $68.9^{\circ} \mathrm{N}$ (named layer I hereafter), the second and third ones are through the longest and thin layer at $69.6^{\circ} \mathrm{N}$ and $71.7^{\circ} \mathrm{N}$ (layer II-A and II-B) and the last one at $70.6^{\circ} \mathrm{N}$ samples the cloud free marine PBL over the Arctic ocean. The attenuated backscatter ratio, $R(z)$, is defined in this paper as the Rayleigh normalized total volume backscatter, only attenuated by the aerosol extinction (see Appendix A). It was derived from vertical profiles averaged over the 4 selected regions, and applying a calibration factor to reference the scattering ratio to 1 in clean air. This factor was calculated using areas with mainly Rayleigh contribution to the IR lidar signal in the altitude range close to the aircraft (e.g. at $69.6^{\circ} \mathrm{N}$ above $5 \mathrm{~km}$ or at $70.3^{\circ} \mathrm{N}$ near $3 \mathrm{~km})$. This was done independently for each wavelength and the consistency of the calibration factor is checked using different aerosol free areas whenever possible. This is the major source of error in the calculation of $R(z)$, and the uncertainty was assumed to be less than $10 \%$ at $532 \mathrm{~nm}$ and $355 \mathrm{~nm}$, less than $20 \%$ at $1064 \mathrm{~nm}$. The latter was derived 


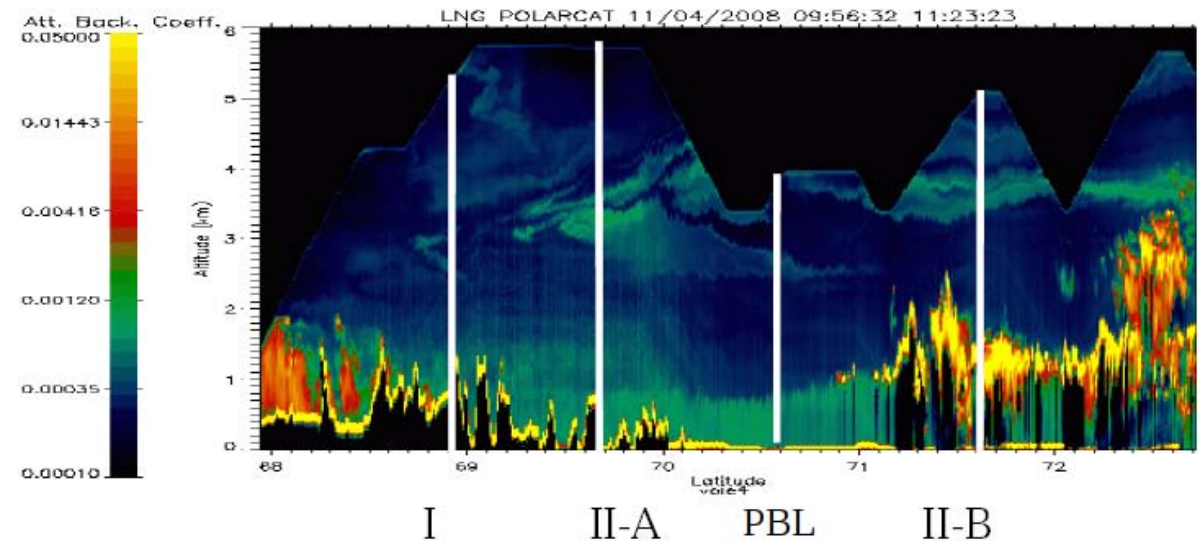

Fig. 2. Vertical cross section of the attenuated $1064 \mathrm{~nm}$ backscatter measured by downward looking lidar between $68^{\circ} \mathrm{N}$ and $72.5^{\circ} \mathrm{N}$. The white vertical lines represent the four profiles, I, II-A, PBL, and II-B.
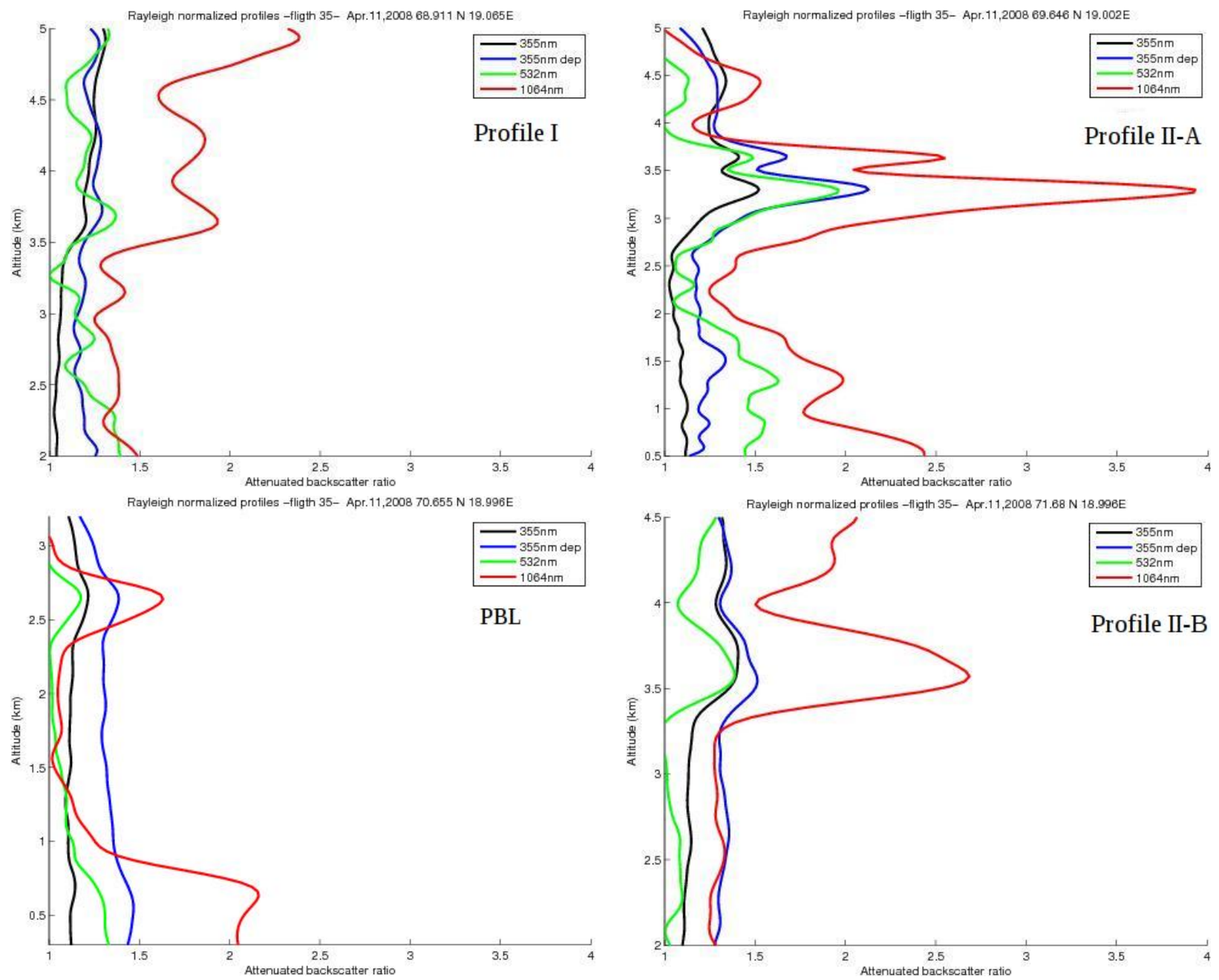

Fig. 3. Lidar vertical profiles of the 20-s averages of the attenuated backscatter ratio at 355, 355 depolarized, 532 and $1064 \mathrm{~nm}$ for the 4 lidar profiles listed in Table 2 . 

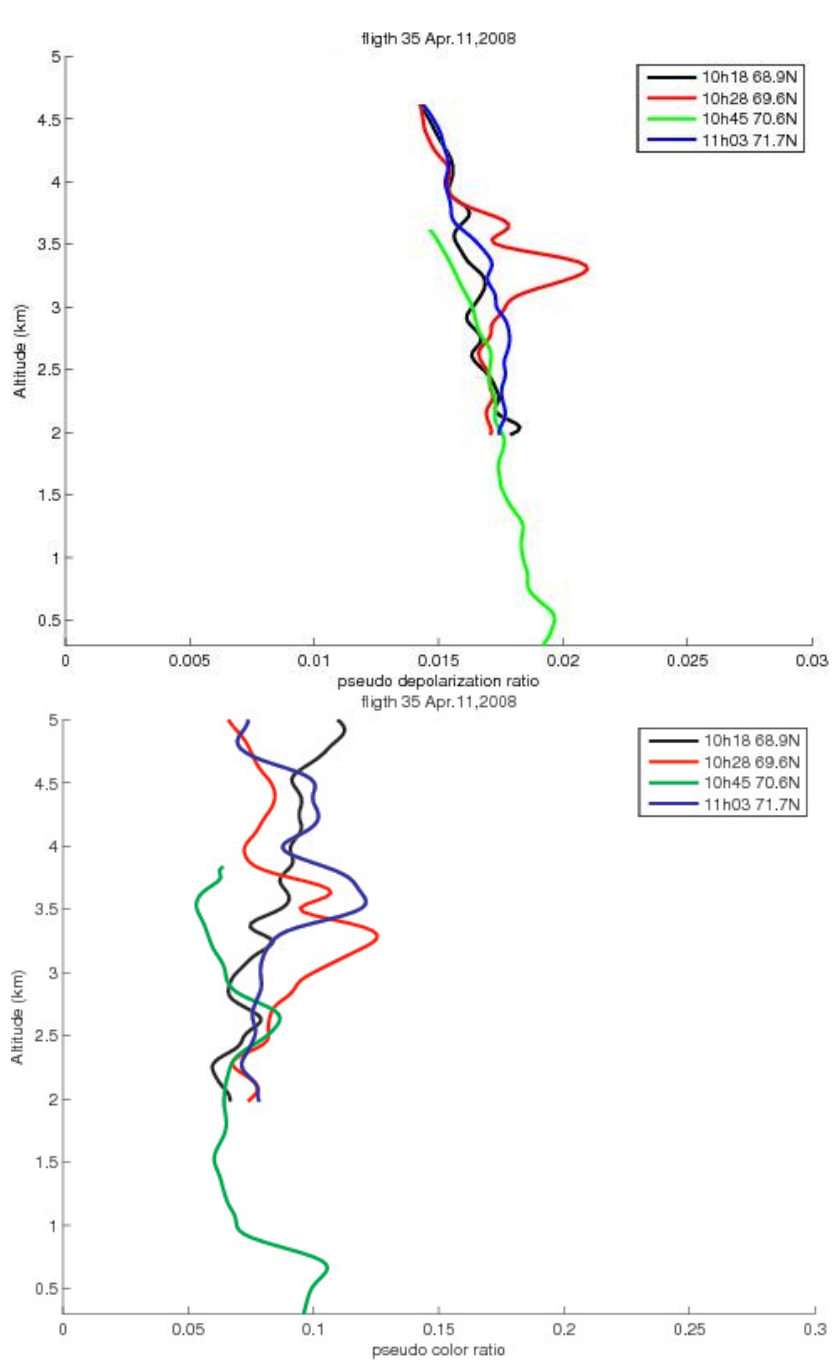

Fig. 4. Vertical profiles of the $355 \mathrm{~nm}$ pseudo depolarization ratio $\delta_{355}$ and the pseudo color ratio between 1064 and $532 \mathrm{~nm}$ for the 4 lidar profiles listed in Table 2 and showed by the white bar in Fig. 2

from a sensitivity study using different possible calibration factors and different flights.

The $R(z)$ vertical profiles for each wavelength and the 4 selected latitudes are given in Fig. 3. For the strongest aerosol layer at $69.6^{\circ} \mathrm{N}$ (layer II-A), the $R$ increase is present in the three wavelength channels. The maximum $R$ value at $532 \mathrm{~nm}$ is of the order of 2 and it corresponds to a 532-nm aerosol backscatter coefficient of the order of $10^{-3} \mathrm{~km}^{-1} \mathrm{sr}^{-1}$ and therefore a small optical depth for layer II-A $\left(\approx 3-410^{-2}\right)$ assuming a 532-nm lidar ratio of the order of $70 \mathrm{sr}$ (Cattrall et al., 2005), i.e. considering for example biomass burning aerosol. For the other layers (I and II-B), $R$ is of the order of 2 at $1064 \mathrm{~nm}$ and between $1.3-1.4$ at $532 \mathrm{~nm}$. Layers with IR values of $R$ less than 1.5 will not be considered in the following discussion.

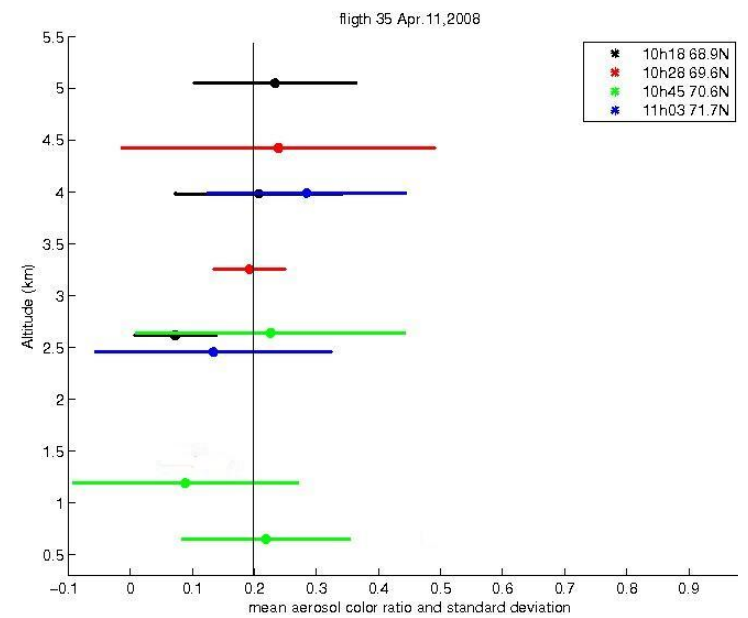

Fig. 5. Vertical profiles of the aerosol color ratio between 1064 and $532 \mathrm{~nm}$ and its standard deviation for the largest layers observed by the airborne lidar at $68.6^{\circ} \mathrm{N} 68.9^{\circ} \mathrm{N} 70.6^{\circ} \mathrm{N}$ and $71.7^{\circ} \mathrm{N}$.

The pseudo depolarization ratios $\delta_{355}$ are shown for the four profiles (Fig. 4a) and it becomes significantly larger than the molecular depolarization only for the layer II-A at $69.6^{\circ} \mathrm{N}$ near $3.2 \mathrm{~km}$ where it is of the order of 0.021 . Notice that it is also larger than the Rayleigh depolarization in the Arctic PBL (0.019). For the layer II-A, the aerosol depolarization ratio, corresponding to a $\delta_{355}$ of 0.021 , is of the order of $3.3 \%$, i.e. a value much smaller than the $532-\mathrm{nm}$ aerosol depolarization ratio reported by Gobbi et al. (2003) for a mountain site in Italy. This would be consistent with a significant fraction of spherical aerosol even though we are able to detect some depolarization in layer II-A.

The pseudo color ratio plot for the four profiles shows also largest values $(0.13 \pm 0.01)$ in layer II-A at $69.6^{\circ} \mathrm{N}$ (Fig. $4 \mathrm{~b}$ ). The smaller values $(0.08 \pm 0.02)$ in the southern layer are consistent with the hypothesis of smaller aerosol size in layer I. The pseudo color ratio in layer II-B at $71.7^{\circ} \mathrm{N}$ near $3.5 \mathrm{~km}$ $(0.11 \pm 0.02)$ is intermediate between the two previous cases. The main characteristics of the aerosol layers identified in Fig. 3 are listed in Table 2 with the expected uncertainty on the pseudo color and depolarization ratio. The aerosol color ratio, which is proportional to $\left(R_{1.06}-1\right) /\left(R_{0.53}-1\right)$, is also listed in Table 2 as it is generally directly linked to the aerosol backscatter wavelength dependency and reported in previous studies on tropospheric aerosols (see Appendix A for differences between the two ratios).

For all the layers,our values of color ratios are much smaller than the reported values of Cattrall et al. (2005). In their work, the color ratios are calculated using data from the AERONET photometer worldwide network at 550 and $1020 \mathrm{~nm}$, and for larger aerosol optical depths $(>0.1)$. Their values are ranging between 0.5 (polluted layers) to 1 (dust layers), whereas the Angstrom coefficient determined from 
Table 2. Aerosol layer characteristics from the airborne lidar observations.

\begin{tabular}{lccccccc}
\hline $\begin{array}{c}\text { Lidar } \\
\text { layer }\end{array}$ & $\begin{array}{c}\text { Layer } \\
\text { latitude }\end{array}$ & $\begin{array}{c}\text { Altitude } \\
\text { range, } \mathrm{km}\end{array}$ & $\begin{array}{c}\beta_{532} \\
\mathrm{~km}^{-1} \mathrm{sr}^{-1}\end{array}$ & $\begin{array}{c}\text { Aerosol } \\
\text { color ratio }\end{array}$ & $\begin{array}{c}\text { Pseudo } \\
\text { color ratio }\end{array}$ & $\begin{array}{c}\text { Aerosol } \\
\delta_{355}\end{array}$ & $\begin{array}{c}\text { Pseudo } \\
\delta_{355}\end{array}$ \\
\hline I & $68.9^{\circ} \mathrm{N}$ & $3.5-4.5$ & $1.2 \pm 0.110^{-3}$ & $0.21 \pm 0.14$ & $8.5 \pm 1.810^{-2}$ & $2.1 \pm 1.8 \%$ & $1.6 \pm 0.3 \%$ \\
II-A & $69.6^{\circ} \mathrm{N}$ & $2.8-3.8$ & $2.2 \pm 0.210^{-3}$ & $0.19 \pm 0.03$ & $12.5 \pm 1.310^{-2}$ & $3.3 \pm 0.9 \%$ & $2.1 \pm 0.3 \%$ \\
PBL & $70.6^{\circ} \mathrm{N}$ & $<0.8$ & $1.8 \pm 0.210^{-3}$ & $0.24 \pm 0.12$ & $10.4 \pm 1.710^{-2}$ & $5.4 \pm 5.3 \%$ & $1.9 \pm 0.3 \%$ \\
II-B & $71.7^{\circ} \mathrm{N}$ & $3.5-4.5$ & $1.3 \pm 0.110^{-3}$ & $0.20 \pm 0.06$ & $11 \pm 1.610^{-2}$ & $2.1 \pm 1 \%$ & $1.6 \pm 0.2 \%$ \\
\hline
\end{tabular}

extinction coefficients decreases from 2 to 0 . This is comparable to calculations made from the Optical Properties of Aerosols and Clouds (OPAC) package (Hess et al., 1998; Liu et al., 2004). For our observations, corresponding to smaller aerosol optical depths $(<0.04)$ and small backscatter coefficients (1-2 $10^{-3} \mathrm{~km}^{-1} \mathrm{sr}^{-1}$ ), the color ratio is about 0.2 , for all the layers, as reported in Table 2 and in Fig. 5. This corresponds to a wavelength dependence in the backscatter coefficient larger than 2, indicative of small particle sizes. The pseudo color ratio shows slightly smaller values for layer I, with respect to the other ones, but looking at the variability, it does not appear to be fully significant, and no major difference is seen on color ratio (Fig. 5). The overall results of Table 2 however show that the apparently homogeneous layer II may be formed of several aerosol sources since layer II-A and II-B have different optical characteristics. To sumarize, the airborne lidar data show that:

- aerosol layers are identified in the mid-troposphere having very low optical depths $(<0.04)$.

- two layers (I and II) are detected with markedly different vertical structure and backscatter values implying different aerosol sources and probably different transport processes

- layer I has low depolarization and lowest pseudo color ratio related to a very small fraction of coarse size particles

- layer II is not homogeneous with, according to the pseudo color ratio values, larger particles than layer I and even some depolarization in layer II-A.

- pseudo color ratio and aerosol color ratio are smaller than values derived from the AERONET network, mainly because of larger Angstrom coefficient in our study.

To get more insight in the airborne lidar data indications, we have taken advantage of the flight pattern to analyze the in-situ measurements when the aircraft has crossed the layers observed by the lidar.

\subsection{In-situ measurements}

Ozone and carbon monoxide (CO) were measured on the ATR-42 (Nedelec et al., 2003). The CO is especially useful as it can indicate if an air mass has been influenced by combustion processes less than 10-20 days before. Regarding the aerosol concentrations, an optical counter (CPC-3010) measured the number of submicronic particles with sizes larger than $10 \mathrm{~nm}$ and a Passive Cavity Aerosol Spectrometer Probe (PCASP SPP-200) provided the number of particles in 30 size bins between $0.1-3 \mu \mathrm{m}$. Uncertainties up to $10 \%$ have to be taken in account because of difficulties to estimate the correct probe volumic sample flow. In this paper the PCASP data are summed over all the size bins to get a concentration number comparable to the optical counter. Differences between the two numbers are mostly related to a large fraction of small particles $(<100 \mathrm{~nm})$ detected by the optical counter but not seen by the PCASP.

The CO and the aerosol concentrations from the PCASP and the CPC are shown in Fig. 6 for latitudes lesser and greater than $70^{\circ} \mathrm{N}$, respectively the second plot corresponding to the numerous crossing of the layer II identified by the lidar. The CO variability is generally well correlated with the aerosol concentrations is of the order of $100 \mathrm{ppb}$. It is not very different for the southerly flow and the Artic outflow. This variability can be explained by the highly stratified aerosol and chemical composition of the free troposphere as shown by the lidar. The smallest CO values around $130 \mathrm{ppb}$ correspond to the cleanest and oldest air masses, sampled on this flight.

When comparing the PCASP and the optical counter data, one can notice higher concentrations of small particles in the southern section of the flight. This is related to either the removal of larger particles during the transport from midlatitudes or to the generation of new smaller particles. The two hypotheses imply differences for layer I and II in the air mass age since exposure to emissions or in the nature of the emissions (e.g. more $\mathrm{SO}_{2}$ concentrations, Weber et al. (2003) or more organic emissions from continental regions over Northern Europe, Sellegri et al., 2005). A more direct way to demonstrate the larger fraction of very small particles is to plot the size spectrum measured along the flight by a Scanning Mobility Particle Sizer (SMPS) for particle smaller than $300 \mathrm{~nm}$ and the PCASP for larger particles (Fig. 7). 

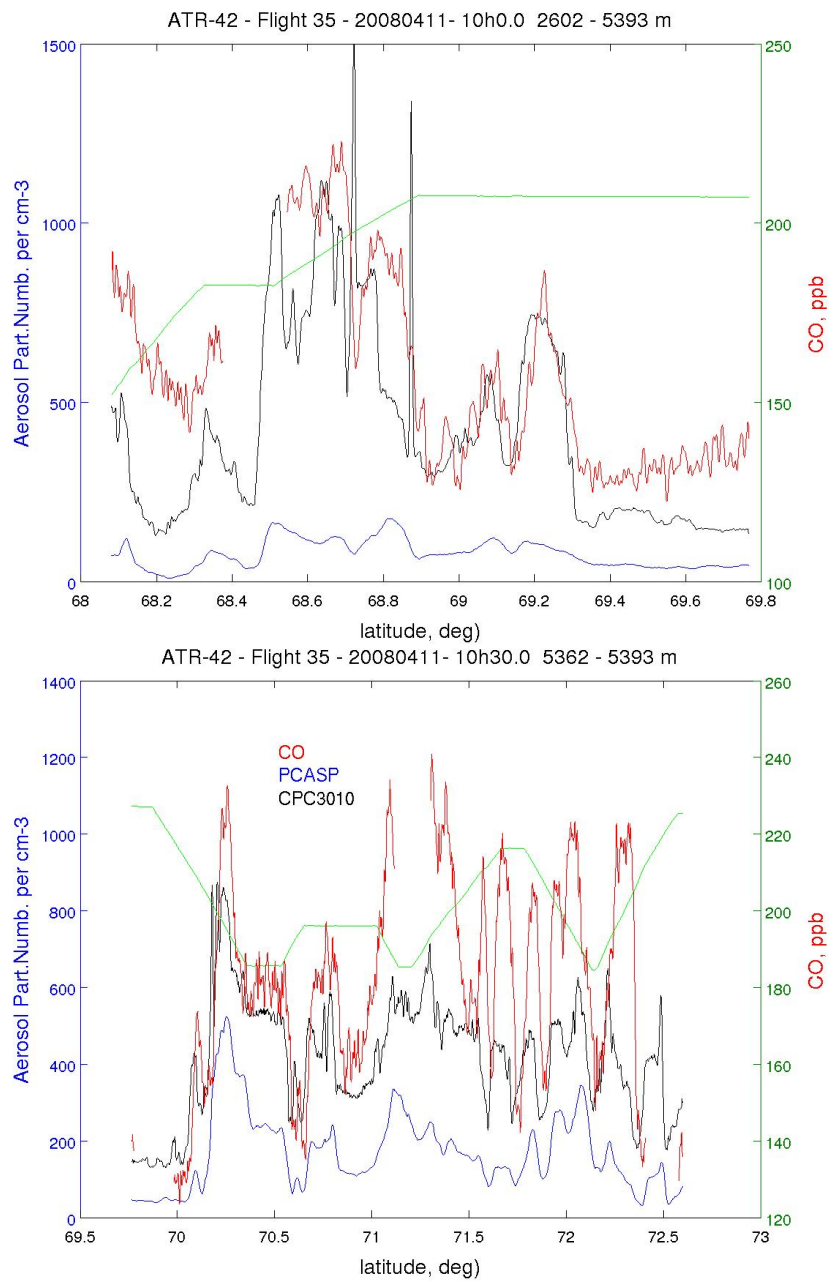

Fig. 6. CO (red) and aerosol concentrations for the PCASP (blue) and CPC (black) along the fligth track for latitudes $<70^{\circ} \mathrm{N}$ (top panel) and latitudes $>70^{\circ} \mathrm{N}$ (bottom panel). Aircraft altitude divided by a factor 5 (green) is plotted in $\mathrm{m}$ using the left vertical axis.

It shows indeed smaller particle sizes (30-200 nm) for the southern section of the flight, while the Artic outflow corresponds to larger particles $(100-300 \mathrm{~nm})$. This is consistent with the interpretation of the differences between the PCASP and the optical counter. It is also noticeable that the fraction of particles with a diameter exceeding $300 \mathrm{~nm}$ are increasing in the layer II-A at $69.6^{\circ} \mathrm{N}$, i.e. where the pseudo color and depolarization ratio are maximum in the lidar data.

The analysis of the in-situ data therefore sheds light on interpretation of the lidar data and we can say that:

- the lidar aerosol layers are mostly related to either biomass burning or urban/industrial sources considering the good correlation between aerosol and CO concentrations. This was already reported in Kampe and Sokolik (2007) and Capes et al. (2008).

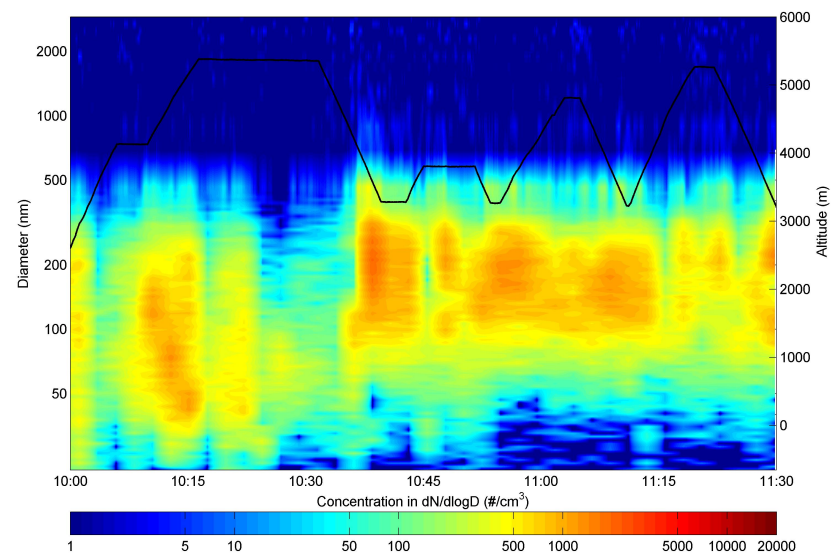

Fig. 7. Size spectrum (nm) measured as a function of time along the flight track by the SMPS $(0.01$ and $0.4 \mu \mathrm{m})$ and PCASP $(0.4-3 \mu \mathrm{m})$. The vertical flight pattern is showed for comparaison with latitude cross-section (black line) in Figs. 13 and 2.

- the pseudo color ratio analysis is consistent with the observed aerosol size distribution showing the largest aerosol size for the layer II-A, even though the aerosol optical depth is small and the variability of this ratio is weak.

To understand the respective influence of the aging and the nature of the sources, air mass origins were investigated using transport modeling.

\section{Modeling of the transport to the Arctic}

\subsection{Description of the FLEXPART simulations}

The origin of the observed air masses was studied using the Lagrangian Particle Dispersion Model (LPDM) FLEXPART version 6 (Stohl et al., 1998, 2002) driven by 6hourly ECMWF analyses (T213L91) interleaved with operational forecasts every $3 \mathrm{~h}$. In addition to classical advection, the LPDM includes turbulent diffusion, parameterizations of sub-grid scale convection and of topographic processes, as well as online computation of potential vorticity (PV) for each air parcel. The fraction of particles with PV $>2$ PVU $\left(1 \mathrm{PVu}=10^{-6} \mathrm{~kg}^{-1} \mathrm{~m}^{2}\right)$ is calculated as a function of time to estimate the probability of transport from or into the stratosphere. Previous studies have shown that a fraction larger than $20 \%$ corresponds to a significant influence of the stratosphere-troposphere exchange (STE) processes. We modified the FLEXPART model to introduce the calculation of the fraction of particles originating below an altitude of $3 \mathrm{~km}$, for three areas corresponding to different emissions of particulate matter and CO: Europe (latitude $<55^{\circ} \mathrm{N}$, longitude $\in\left[-10^{\circ} \mathrm{W} 30^{\circ} \mathrm{E}\right]$ ), Asia (latitude $<55^{\circ} \mathrm{N}$, longitude 


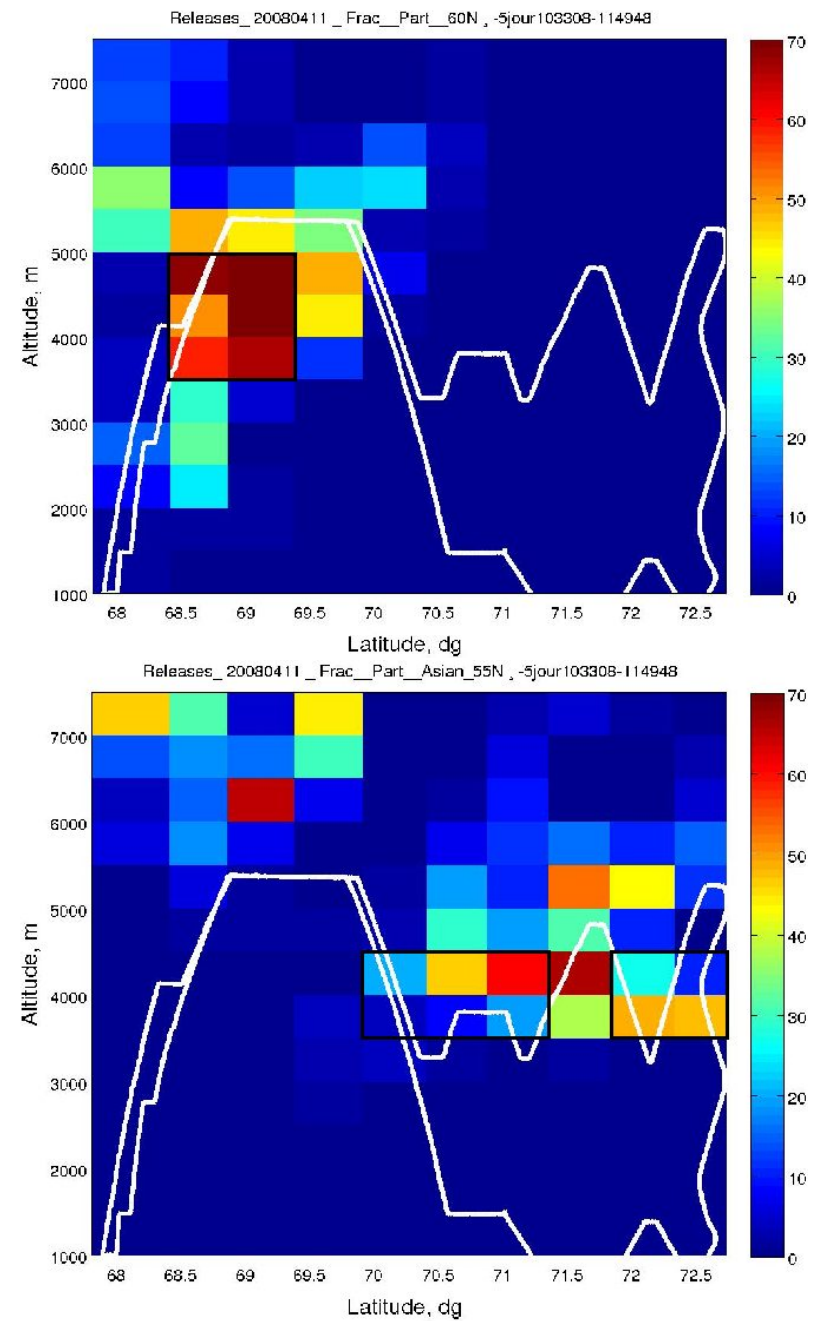

Fig. 8. Meridional vertical cross section of air mass origins calculated by Flexpart for $500 \mathrm{~m} \times 0.5^{\circ} \times 0.5^{\circ}$ boxes. The color scale indicates the fraction of particles in $\%$ being in the European (first figure) and Asian (second figure) lower troposphere $(z \leqslant 3 \mathrm{~km}), 5$ days before the observations. Aircraft altitude is shown in white.

$\in\left[30^{\circ} \mathrm{E} 180^{\circ} \mathrm{E}\right]$, North America (latitude $<55^{\circ} \mathrm{N}$, longitude $\left.\in\left[-180^{\circ} \mathrm{W}-30^{\circ} \mathrm{W}\right]\right)$.

Next we divided the lidar vertical cross-section of Fig. 2 in 130 boxes with the following size: depth of $500 \mathrm{~m}$ and horizontal size of $0.5^{\circ} \times 0.5^{\circ}$. For each box, 2000 particles were released during $60 \mathrm{~min}$ and the dispersion computed for 7 days backward in time. As we focus on layers, our aim is to document their history as long as they remain coherent, i.e. before they undergo strong mixing which, as reported by Methven et al. (2006), becomes significant after 4 days for trajectories arriving above western Europe. The vertical cross-section of the air mass origin can be reconstructed using a plot of the fraction of particles being in the lower troposphere of a given region 5 days before the lidar observa-

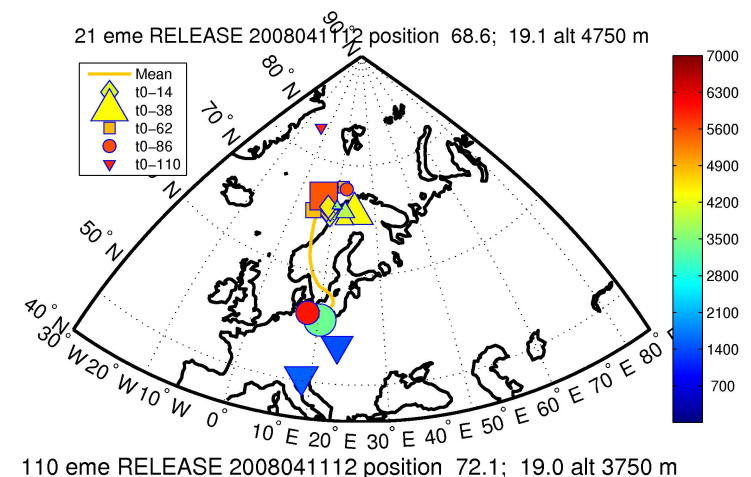

110 eme RELEASE 2008041112 position $72.1 ; 19.0$ alt 3750 m

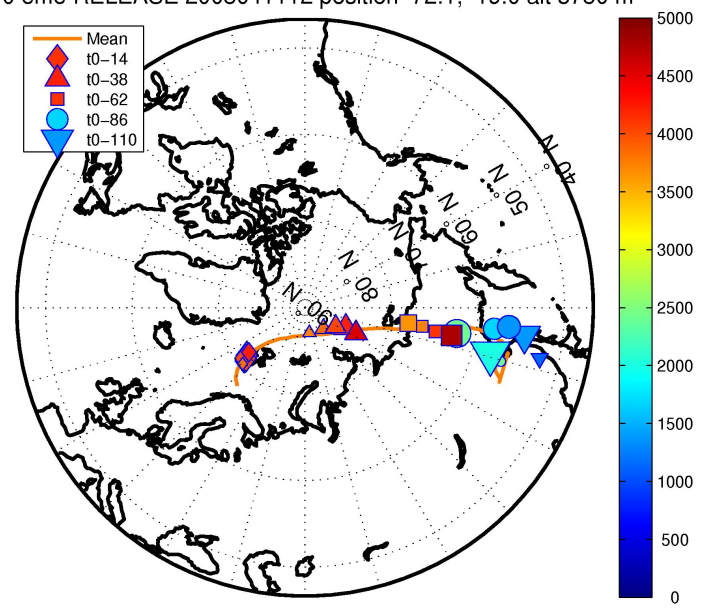

Fig. 9. 5-days FLEXPART backward time position of five clusters of the 2000 particles released between 4 and $4.5 \mathrm{~km}$ at $68.6^{\circ} \mathrm{N}$ (top panel) and between 3.5 and $4 \mathrm{~km}$ at $72.1^{\circ} \mathrm{N}$ (bottom panel) on $11 / 04 / 2008$ at 12:00 UT. The clusters are plotted every $24 \mathrm{~h}$ from $14 \mathrm{~h}$ before observation, the color corresponds to their altitude, and the size of each cluster is proportional to the number of particles.

tions (Fig. 8). Comparison of the cross-sections for different transport times showed that the cross sections of the air mass origins 4 to 6 days before the observations.

The transport pathway for the ensemble of 2000 particles released in a given box can also be described by the position of 5 clusters identified among the particle plume every $24 \mathrm{~h}$. Two examples are given in Fig. 9 for a box in the southern section of the flight mainly influenced by the European emissions and a box in the northern section where air masses were coming from Asia. The size of the clusters corresponds to the number of particles included in the cluster and the color to its altitude. The color of the mean trajectory of the particles is the altitude of the ending point. If the layer remains coherent the 5 clusters (or at least the largest ones) stay close to each other. Often the dispersion of the clusters is too large after 4-5 days to identify a direct link with a single source region or to be able to establish a Lagrangian connection between two different observations. 

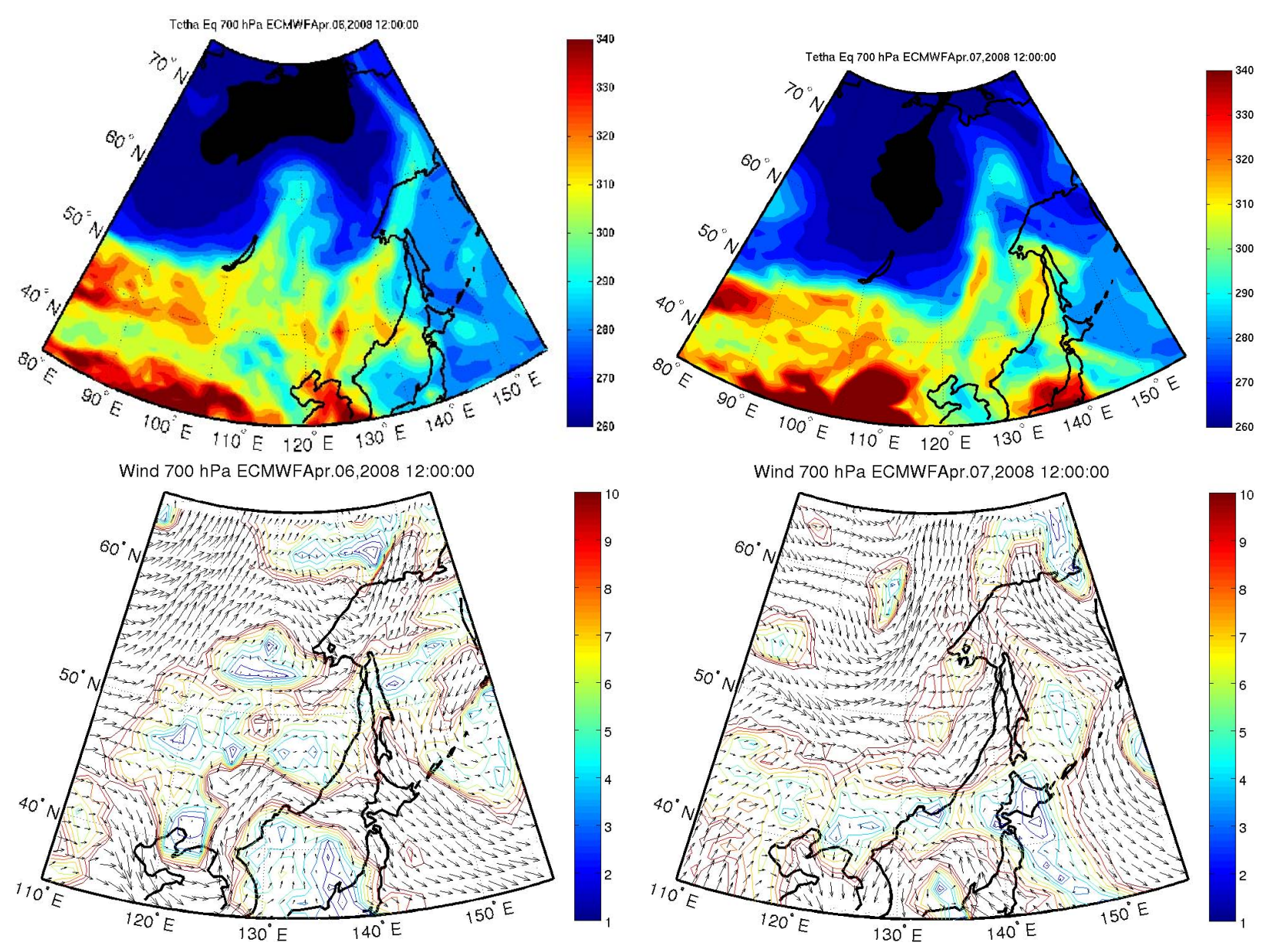

Fig. 10. ECMWF $700 \mathrm{hPa}$ equivalent potential temperature in $\mathrm{K}$ (top row) and ECMWF $700 \mathrm{hPa}$ wind field (bottom row) for the $06 / 04 / 2008$ (left column) and 07/04/2008 (right column) at 12:00 UT. Colored isolines are wind speed in $\mathrm{m} \mathrm{s}^{-1}$.

\subsection{Air mass origins and CALIPSO overpasses}

The cross-section in Fig. 8 nicely shows that the measurement area between 3.5 and $5 \mathrm{~km}$ in the southern section $\left(<70^{\circ} \mathrm{N}\right)$ is mainly related to European emissions with a fraction of particles larger than $30 \%$ coming from the European PBL. The area corresponding to the largest lidar signal comes from central Europe with a significant upward motion from the PBL (altitude $<2 \mathrm{~km}$ ) to the $4 \mathrm{~km}$ altitude range above Denmark (Fig. 9a). This took place over 3.5 days because of the combined influence of two Low pressure systems: one over the North Sea and the other one over the Western Mediterranean sea. Central European emissions first transported by the cold conveyor belt of the southernmost low were then further uplifted in the warm conveyor belt of the northernmost Low.

The aerosol layer observed in the northern section of the flight was transported from Asia as shown by the crosssection of the Asian fraction where boxes with fraction larger than $30 \%$ matches exactly the sawtooth motion of the aircraft between $70.5^{\circ} \mathrm{N}$ and $72.5^{\circ} \mathrm{N}$. An example of a trajectory for the box at $72^{\circ} \mathrm{N}, 3.7 \mathrm{~km}$ (Fig. 9b) shows that the upward motion took place in a frontal system developing above North Eastern China from 5 April to 7 April (see the $\theta_{e}$ map showing the position of the low level front and the advection of warm and humid air mass toward the Arctic in Fig. 10).

The influence of STE below $6 \mathrm{~km}$ remains negligible (the PV fraction in the FLEXPART runs are always less than $10 \%$ ) and the clean region of the lidar section above $3.5 \mathrm{~km}$ between $69.5^{\circ} \mathrm{N}$ and $70^{\circ} \mathrm{N}$ remains influenced by the European emission but uplifting is mainly driven by the April 7 low pressure over the North Sea. The dominant European sources are then from the southern coast of the Baltic sea, where lower $\mathrm{CO}$ emissions are expected. Aerosols were probably washed out in the northern part of the warm conveyor belt where heavy precipitation is often encountered at low level (Bethan et al., 1996).

To be more specific about the geographical extent of the Asian and European sources responsible for the aerosol and $\mathrm{CO}$ increase, we have also used the map of the potential 

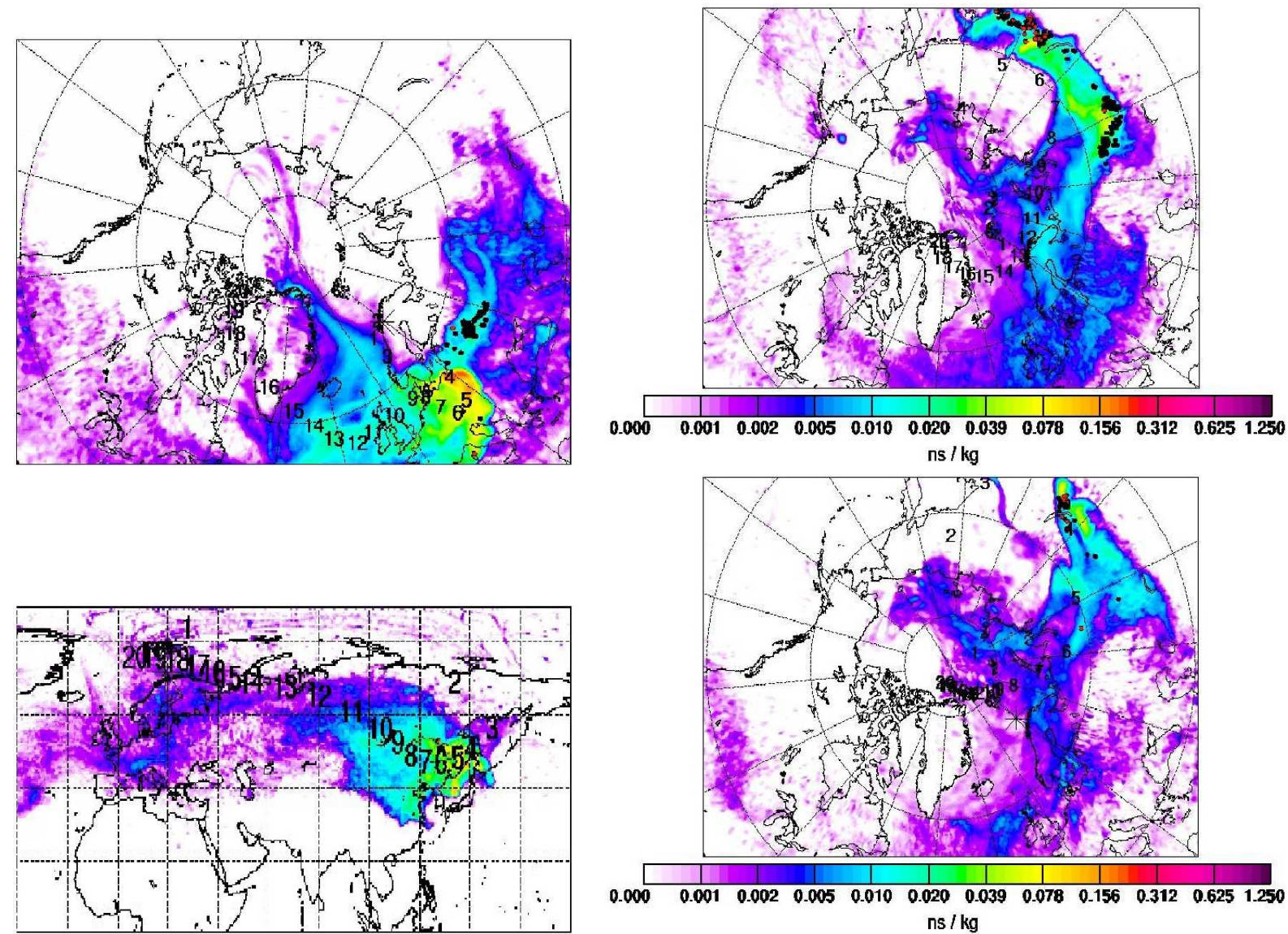

$\mathrm{ns} / \mathrm{kg}$

Fig. 11. Potential Emission Sensivity (PES) in $\mathrm{ns} / \mathrm{kg}$ for 4 points of the flight track $68.8^{\circ} \mathrm{N}-4500 \mathrm{~m}, 70.2^{\circ} \mathrm{N}-4200 \mathrm{~m}, 72^{\circ} \mathrm{N}-3600 \mathrm{~m}$ and $72.4^{\circ} \mathrm{N}-5250 \mathrm{~m}$. Numbers indicate elapsed time in days since emission along the mean trajectory. (see http://transport.nilu.no/ flexpart-projects?cmp=POLARCAT_FRANCE).

emission sensitivity (PES) described in Seibert and Frank (2004) and calculated for different positions along the aircraft track by John Burkhart for the POLARCAT project (web site http://transport.nilu.no/flexpart-projects). The PES is shown in Fig. 11 for 4 different latitudes along the flight cross-section: $68.6^{\circ} \mathrm{N}$ (European plume), $70.2^{\circ} \mathrm{N}, 72^{\circ} \mathrm{N}$, $72.4^{\circ} \mathrm{N}$ (Asian plume). The $72.4^{\circ} \mathrm{N}$ and $72^{\circ} \mathrm{N}$ air masses correspond to respectively the aerosol layer at $5 \mathrm{~km}$ and at $3.7 \mathrm{~km}$ in the northernmost part of the lidar cross-section. We can see that the European emissions related to our observations are mainly from Eastern Europe and that the air mass lifetime is of the order of 4-5 days. For the Asian plume, we can see that it cannot be regarded as a single layer with a similar history but most likely to two different plumes: one is related to the fire emissions which took place in April 2008 over Siberia (see the 10-day mean fire map plot measured by MODIS from 31/03/2008 to 09/04/2008 in Fig. 12) east of Lake Baikal and the other one is related to the anthropogenic emissions from North Eastern Asia (Streets and Waldhoff, 2000). The strong impact of the spring 2008 Siberian fires on the atmospheric composition have been already observed over Alaska (Warneke et al., 2009) and by the satellite observations (Coheur et al., 2009).

Using air mass trajectory estimates similar to the results shown in Fig. 9, one can look for the CALIPSO satellite tracks coinciding with the transport of these aerosol layers to the region of the aircraft measurements. This was done for three groups of trajectories corresponding to the boxes of Fig. 8 which are within the black rectangles indicated in this figure: (i) the first area near $69^{\circ} \mathrm{N}$ (six trajectories) matches the European plume (layer I in the lidar data), (ii) the second one at $4 \mathrm{~km}$ near $70.5^{\circ} \mathrm{N}$ (six trajectories) matches the southern part of the Asian plume (layer II-A) and (iii) the last rectangle at $4 \mathrm{~km}$ near $72^{\circ} \mathrm{N}$ (four trajectories) corresponds to the northern part of the Asian plume (layer II-B). A CALIPSO track was selected if the time and horizontal position of the satellite overpass was less than, respectively $2 \mathrm{~h}$ and $200 \mathrm{~km}$, from the air mass positions in the FLEXPART runs. The track sections (line) and the FLEXPART air mass positions (stars) are shown in Fig. 13 where the color scale 


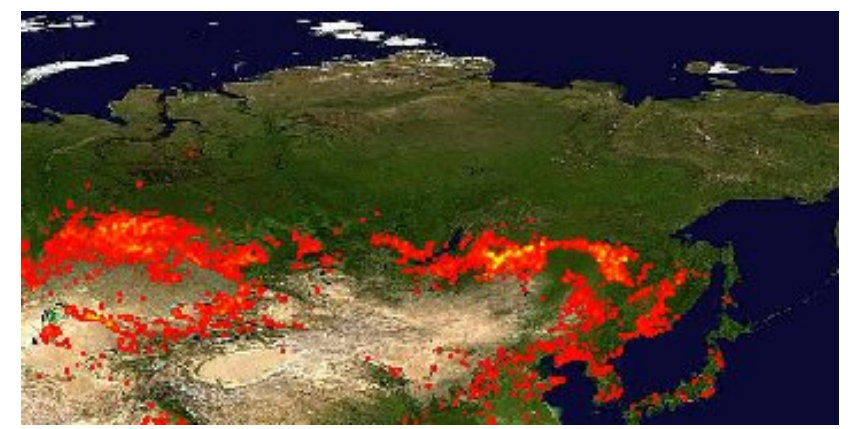

Fig. 12. Fires detected by MODIS over a 10-day period 31/03/2008 to $09 / 04 / 2008$. Each colored dot indicates a location with at least one fire during the compositing period. Color ranges from low (red) to high (yellow) fire counts.

corresponds to the elapsed time between the CALIPSO observations and the aircraft observations. One can see that the evolution of the aerosol content of the 3 selected groups can be analysed for a 6 day period for the Asian plume and a 4 day period for the European plume, i.e. the time corresponding to the transport from the source region. The selected CALIPSO observations are coming from the same source region for group (ii) and (iii) but the pathways are slightly different. The air masses and the corresponding CALIPSO observations remain over the continent with the northward transport near $135^{\circ} \mathrm{E}$ three days before for group (iii), i.e. the northern section of the plume. The group (ii) shows a longer pathway with the northward transport more often over the Pacific ocean and even toward Alaska before coming back west to Scandinavia. Several CALIPSO overpasses are indeed above Alaska for group (ii).

Even though there are different pathways for group (ii) and (iii), we will not distinguish the two groups any further as their air masses are both connected to the position of the Siberian fires and north-east Asian emissions. The use of CALIPSO to distinguish aerosol layers related to these two sources will have to be deduced from the actual latitude/longitude of the detected layers in the CALIPSO observations over Asia.

Notice that there is a likely Lagrangian connection between aircraft observations made in Alaska between 4 and 7 April and the lidar observations of group (ii). This will be studied in a future paper using a Lagrangian model for aerosol aging.

\section{Optical properties of the aerosol plumes using CALIOP}

The level-2.1 version 2.01 CALIOP aerosol data products have been analysed along the selected CALIPSO track using the 5-km horizontal average profiles (Liu et al., 2009).

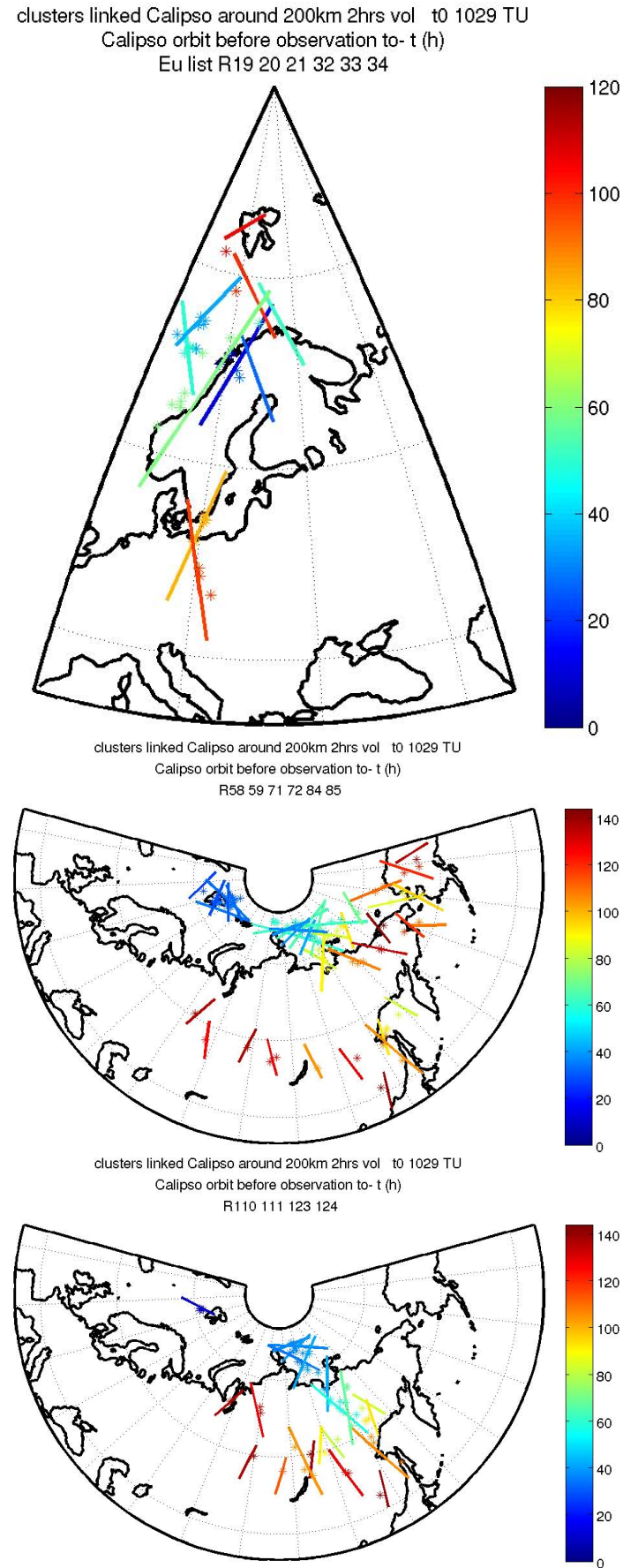

Fig. 13. Calipso track sections (line) and FLEXPART air mass positions $(*)$ along FLEXPART trajectories initialized in the black rectangles of Fig. 8 (top left panel for $695^{\circ} \mathrm{N}$, top right and bottom panel for respectively the $70.5^{\circ} \mathrm{N}$ and $72^{\circ} \mathrm{N}$ rectangles). The colors scale indicates the elapsed time in hour between the CALIPSO observation and the aircraft observation. 
Table 3a. Aerosol layer characteristics from the CALIPSO observations for the backward FLEXPART model run initialized at $69.5^{\circ} \mathrm{N}-$ $72.5^{\circ} \mathrm{N}, 3.5-4.5 \mathrm{~km}$ (Layer II-A and II-B). Lines are colored to indicate Siberian fires (light brown), mixed Asian sources south of 52N (gold and red to indicate when dust are expected to influence the mixture) from trajectory analysis.

\begin{tabular}{|c|c|c|c|c|c|c|c|c|c|}
\hline Date & $\begin{array}{l}\text { Time } \\
\text { UT }\end{array}$ & $\begin{array}{c}\text { CALIOP } \\
\text { Start } \\
\text { Lat./Lon }\end{array}$ & $\begin{array}{c}\text { End } \\
\text { Lat./Lon }\end{array}$ & $\begin{array}{c}\text { Flexpart } \\
\text { layer } \\
\text { alt, km }\end{array}$ & $\begin{array}{c}\text { Mean } \\
\beta_{532} \\
\mathrm{~km}^{-1} \mathrm{sr}^{-1}\end{array}$ & $\begin{array}{c}\text { Pseudo } \\
\text { Color } \\
\text { ratio }\end{array}$ & $\begin{array}{c}\text { Pseudo } \\
\text { Mean } \\
\delta_{532}\end{array}$ & $\begin{array}{c}\text { Aerosol } \\
\text { Color } \\
\text { ratio }\end{array}$ & $\mathrm{FCF}$ \\
\hline $05 / 04$ & $03: 21$ & $51.3 / 135.8$ & $52.4 / 135.4$ & $5.2-7.2$ & $22 \pm 4.10^{-4}$ & $0.36 \pm 0.16$ & $0.12 \pm 0.17$ & $0.54 \pm 0.51$ & $\mathrm{D}$ \\
\hline $05 / 04$ & 05:00 & $51.73 / 110.94$ & $52.38 / 110.63$ & $2.2-4.2$ & $18 \pm 3.10^{-4}$ & $0.33 \pm 0.16$ & $0.10 \pm 0.11$ & & \\
\hline $05 / 04$ & $12: 28$ & $61.81 /-146.33$ & $63.65 /-144.88$ & $2.1-4.1$ & $39 \pm 22.10^{-4}$ & $0.38 \pm 0.45$ & $0.11 \pm 0.15$ & & \\
\hline $05 / 04$ & $17: 25$ & $42.55 / 130.16$ & $47.77 / 132.06$ & $1-2.2$ & $39 \pm 12.10^{-4}$ & $0.39 \pm 0.18$ & $0.07 \pm 0.06$ & $0.55 \pm 0.71$ & P.D. \\
\hline $05 / 04$ & $19: 04$ & $56.34 / 111.3$ & $61.41 / 114.49$ & $3.7-5.7$ & $14 \pm 3.10^{-4}$ & $0.27 \pm 0.19$ & $0.04 \pm 0.04$ & $0.72 \pm 1.28$ & P.D. \\
\hline $05 / 04$ & $20: 43$ & $56.26 / 86.54$ & $57.09 / 87$ & $3.2-5.2$ & $16 \pm 3.10^{-4}$ & $0.3 \pm 0.14$ & $0.06 \pm 0.04$ & $0.7 \pm 0.87$ & P.D. \\
\hline $05 / 04$ & $22: 21$ & $59.06 / 63.46$ & $62.42 / 65.8$ & $5.3-7.3$ & $12 \pm 2.10^{-4}$ & $0.32 \pm 0.15$ & $0.09 \pm 0.05$ & & \\
\hline $05 / 04$ & $22: 21$ & $68.55 / 71.74$ & $69.83 / 73.41$ & $5.5-7.5$ & $13 \pm 3.10^{-4}$ & $0.26 \pm 0.17$ & $0.11 \pm 0.06$ & & \\
\hline $06 / 04$ & 04:05 & $50.26 / 125.48$ & $51.4 / 124.98$ & $1.5-3.5$ & $25 \pm 3.10^{-4}$ & $0.33 \pm 0.16$ & $0.06 \pm 0.11$ & $0.58 \pm 0.52$ & P.D. \\
\hline $06 / 04$ & $07: 22$ & $56.41 / 73.06$ & $57.06 / 72.7$ & $5-7$ & $15 \pm 2.10^{-4}$ & $0.3 \pm 0.17$ & $0.11 \pm 0.11$ & $0.59 \pm 0.65$ & $\mathrm{D}$ \\
\hline $06 / 04$ & $13: 12$ & $65.12 /-154.4$ & $67.1 /-152.42$ & $3.7-6.5$ & $15 \pm 5.10^{-4}$ & $0.05 \pm 0.4$ & $0.07 \pm 0.07$ & & \\
\hline 06/04 & $14: 50$ & $65.59 /-178.68$ & $65.72 /-178.56$ & $4.8-6.8$ & $15 \pm 3.10^{-4}$ & $0.53 \pm 0.35$ & $0.10 \pm 0.08$ & & \\
\hline $06 / 04$ & $19: 47$ & $57.97 / 101.42$ & $58.62 / 101.81$ & $4.7-6.7$ & $10 \pm 1.10^{-4}$ & $0.13 \pm 0.1$ & $0.04 \pm 0.02$ & $0.54 \pm 1.2$ & $\mathrm{D}$ \\
\hline $06 / 04$ & $23: 51$ & $58.61 /-175.44$ & $59.43 /-175.96$ & $4.9-6.9$ & $21 \pm 4.10^{-4}$ & $0.22 \pm 0.18$ & $0.09 \pm 0.11$ & & \\
\hline $07 / 04$ & 03:09 & $47.42 / 140.54$ & $50.5 / 139.28$ & $1-3.4$ & $40 \pm 12.10^{-4}$ & $0.55 \pm 0.18$ & $0.13 \pm 0.18$ & $0.76 \pm 0.82$ & $\mathrm{D}$ \\
\hline $07 / 04$ & 03:09 & $50.81 / 139.14$ & $51.78 / 138.71$ & $1-2.8$ & $35 \pm 12.10^{-4}$ & $1.02 \pm 0.61$ & $0.11 \pm 0.17$ & $1.59 \pm 2.39$ & $\mathrm{D}$ \\
\hline 07/04 & $04: 48$ & $52.78 / 113.53$ & $53.26 / 113.3$ & $2.7-4.7$ & $32 \pm 7.10^{-4}$ & $0.33 \pm 0.14$ & $0.00 \pm 0.08$ & $0.47 \pm 0.48$ & S \\
\hline $07 / 04$ & $16: 20$ & $72.81 / 155.56$ & $73.83 / 157.66$ & $4.7-7$ & $13 \pm 2.10^{-4}$ & $0.27 \pm 0.13$ & $0.02 \pm 0.02$ & & \\
\hline $07 / 04$ & $17: 13$ & $52.04 / 136.95$ & $56.15 / 139.01$ & $1-3.3$ & $27 \pm 6.10^{-4}$ & $0.31 \pm 0.25$ & $0.04 \pm 0.03$ & & \\
\hline $07 / 04$ & $17: 13$ & $59.11 / 140.74$ & $64.18 / 144.49$ & $1-3.4$ & $27 \pm 8.10^{-4}$ & $0.31 \pm 0.15$ & $0.02 \pm 0.03$ & & \\
\hline $07 / 04$ & $17: 59$ & $75.09 / 136.02$ & $76.98 / 141.93$ & $5-7.3$ & $13 \pm 2.10^{-4}$ & $0.27 \pm 0.14$ & $0.03 \pm 0.04$ & & \\
\hline $07 / 04$ & $18: 52$ & $58.94 / 115.92$ & $59.59 / 116.33$ & $5-7$ & $11 \pm 1.10^{-4}$ & $0.24 \pm 0.13$ & $0.07 \pm 0.04$ & $0.88 \pm 1.06$ & $\mathrm{D}$ \\
\hline 08/04 & $00: 35$ & $76.26 / 150$ & $76.8 / 148.18$ & $5-7.4$ & $17 \pm 4.10^{-4}$ & $0.27 \pm 0.2$ & $0.16 \pm 0.11$ & & \\
\hline $08 / 04$ & $02: 14$ & $61.95 / 146.76$ & $63.27 / 145.72$ & $1-3$ & $25 \pm 4.10^{-4}$ & $0.3 \pm 0.1$ & $0.04 \pm 0.11$ & & \\
\hline $08 / 04$ & $17: 56$ & $59.82 / 130.39$ & $64.89 / 134.3$ & $2.1-6.6$ & $17 \pm 3.10^{-4}$ & $0.25 \pm 0.14$ & $0.04 \pm 0.03$ & & \\
\hline 08/04 & $20: 21$ & $80.38 / 126.27$ & $80.71 / 129.88$ & $4.8-7.4$ & $13 \pm 2.10^{-4}$ & $0.28 \pm 0.13$ & $0.00 \pm 0.08$ & & \\
\hline $08 / 04$ & $22: 00$ & $81.3 / 113.75$ & $81.52 / 118.4$ & $4.8-7.4$ & $15 \pm 2.10^{-4}$ & $0.3 \pm 0.14$ & $0.03 \pm 0.09$ & & \\
\hline
\end{tabular}

D: Dust. C.C.: Clean Continental. P.D.: Polluted Dust. S: Smoke.

We have considered the aerosol layer properties when the aerosol layer altitude is less than $1 \mathrm{~km}$ away from the air mass altitudes calculated by FLEXPART. Two additional conditions are: a minimum horizontal averaging of $80 \mathrm{~km}$ and a $3 \%$ minimum threshold value for the layer optical depth at $532 \mathrm{~nm}$ to be faithfully analyzed. The last two conditions are necessary considering the small aerosol optical depths of the layers revealed by the airborne lidar observations. For a given CALIPSO track, the average position of all the nearby FLEXPART air masses is calculated and the track is analysed over a $\pm 300 \mathrm{~km}$ distance around this average position. The mean 532-nm attenuated backscatter, the pseudo color ratio between 1064 and $532 \mathrm{~nm}$ and the 532-nm volume depolarization ratio are reported for all the layers which fullfilled the previous conditions in Tables $3 \mathrm{a}$ and $3 \mathrm{~b}$ for the FLEXPART trajectories of group (ii) and (iii) and in Table 4 for the group (i). The comparison between the CALIPSO tracks in Fig. 13 and the time and position of the detected layers show that $65 \%$ and $50 \%$ of the CALIOP data exhibit aerosol layers with optical depths $>0.03$ for the Asian plumes (Table $3 a, 3 b$ ) and the European plume (Table 4) respectively. We can notice that the uncertainties in the color ratio and the depolarization ratio are often very large and cannot be used for a truly quantitative analysis of the aerosol composition and evolution. The largest possible ratios (i.e. the mean+the standard deviation) still contain a meaningful indication about the possible source and the rough evolution of the optical properties (see Omar et al. (2009) for interpretation of the color ratio and the depolarization ratio for aerosol classification). The Cloud Aerosol Discrimination (CAD) score have been calculated for the aerosol layers listed in Tables 3a, 3b, 4. They are always larger than $50 \%$ and $3 / 4$ of the CAD values are even 
Table 3b. continue from Table 3a, layers in the area where the aircraft flew are indicated in green.

\begin{tabular}{cccccccccc}
\hline Date & $\begin{array}{c}\text { Time } \\
\text { UT }\end{array}$ & $\begin{array}{c}\text { CALIOP } \\
\text { Start } \\
\text { Lat./Lon }\end{array}$ & $\begin{array}{c}\text { End } \\
\text { Lat./Lon }\end{array}$ & $\begin{array}{c}\text { Flexpart } \\
\text { layer } \\
\text { alt, } \mathrm{km}\end{array}$ & $\begin{array}{c}\text { Mean } \\
\beta_{532} \\
\mathrm{~km}^{-1} \mathrm{sr}^{-1}\end{array}$ & $\begin{array}{c}\text { Pseudo } \\
\text { Color } \\
\text { ratio }\end{array}$ & $\begin{array}{c}\text { Pseudo } \\
\text { Mean } \\
\delta_{532}\end{array}$ & $\begin{array}{c}\text { Aerosol } \\
\text { Color } \\
\text { ratio }\end{array}$ & FCF \\
\hline $09 / 04$ & $02: 57$ & $67.82 / 130.51$ & $68.44 / 129.77$ & $4-6.9$ & $21 \pm 5.10^{-4}$ & $0.5 \pm 0.19$ & $0.08 \pm 0.20$ & & \\
$09 / 04$ & $17: 47$ & $71.9 / 132.25$ & $75.98 / 141.63$ & $3.8-5.8$ & $21 \pm 6.10^{-4}$ & $0.29 \pm 0.12$ & $0.03 \pm 0.03$ & & \\
$09 / 04$ & $19: 26$ & $78.32 / 126.06$ & $80.65 / 143.1$ & $3-6.3$ & $16 \pm 2.10^{-4}$ & $0.32 \pm 0.12$ & $0.03 \pm 0.07$ & & \\
$09 / 04$ & $21: 05$ & $80.89 / 121.22$ & $81.16 / 125.21$ & $4.1-6.1$ & $14 \pm 2.10^{-4}$ & $0.35 \pm 0.18$ & $0.00 \pm 0.06$ & & \\
$10 / 04$ & $02: 02$ & $77.56 / 23.72$ & $79.66 / 35.26$ & $4.6-7.4$ & $14 \pm 2.10^{-4}$ & $0.26 \pm 0.15$ & $0.03 \pm 0.07$ & $0.55 \pm 0.65$ & C.C. \\
$10 / 04$ & $03: 40$ & $81.71 / 39.83$ & $81.81 / 47.08$ & $3.7-7.4$ & $20 \pm 4.10^{-4}$ & $0.68 \pm 0.36$ & $0.03 \pm 0.12$ & & \\
$10 / 04$ & $05: 19$ & $81.8 / 20.22$ & $81.82 / 24.04$ & $3.7-6.7$ & $17 \pm 2.10^{-4}$ & $0.15 \pm 0.09$ & $0.03 \pm 0.09$ & $0.25 \pm 0.3$ & C.C. \\
$10 / 04$ & $06: 58$ & $81.32 / 19.38$ & $81.68 / 10.17$ & $3.7-7.4$ & $15 \pm 2.10^{-4}$ & $0.25 \pm 0.17$ & $0.05 \pm 0.11$ & $0.46 \pm 0.56$ & C.C. \\
$11 / 04$ & $02: 45$ & $73.66 / 1.25$ & $75.67 / 6.29$ & $3-5.6$ & $16 \pm 2.10^{-4}$ & $0.27 \pm 0.12$ & $0.02 \pm 0.03$ & $0.62 \pm 0.62$ & S \\
\hline
\end{tabular}

D: Dust. C.C.: Clean Continental. P.D.: Polluted Dust. S: Smoke.

larger than $75 \%$ for the layers discussed in this work. This is a good indication that the features detected by CALIOP are indeed aerosol layers (Eguchi et al., 2009).

Like for the airborne lidar analysis, the aerosol color ratio is also reported in Tables $3 \mathrm{a}, 3 \mathrm{~b}, 4$. The error on this ratio is larger than the error on the pseudo ratio, with values ranging between $100 \%$ and $200 \%$. This ratio varies between 0.25 and 0.7 for the smallest error (100\%), and is close to 0.5 on average for layers identified in Table 3a. It is larger than the airborne lidar values of 0.2 reported in Table 2 .

We however have to consider attenuation above the aircraft to more directly compare both values. Assuming clean air, considering $5 \mathrm{~km}$ as an average altitude flight, and neglecting molecular scattering at $1064 \mathrm{~nm}$ leads to a overestimation of about $15 \%$ of space values with respect to aircraft ones. Including upper level aerosols would lead to an additional increase of the same order, which would make the corrected color ratio derived from space measurements to be about 0.35 . This is also the same correction for the comparison of the pseudo color ratios. This appears acceptable due to the large error bar (mostly linked to calibration error) on this quantity, but also because CALIOP can hardly detect layers with small optical depths $(>0.03)$ and Angstrom coefficient larger than 2 . The CALIOP aerosol color ratio are more comparable to the work of Cattrall et al. (2005) near the Asian sources where there are backscatter ratio $(R>3)$ and where the aerosol color ratio are of the order of $0.6-0.7$ (see layers colored in gold Table $3 \mathrm{a}$ and discussion hereafter on source attribution). This is consistent with a mixture of pollution (color ratio of 0.5 ) and dust aerosol (color ratio of 1).

The analysis of the two tables shows that the CALIOP layers detected in the region $65-85^{\circ} \mathrm{N}, 10-30^{\circ} \mathrm{E}$ (i.e. in the vicinity of the aircraft measurement zone and colored in green in table $3 \mathrm{~b}$ exhibit moderate $532-\mathrm{nm}$ backscatter values (1.4-1.7 $10^{-3} \mathrm{~km}^{-1} \mathrm{sr}^{-1}$, i.e. a backscatter ratio $R$ between
1.6-1.9), low color ratio $(\leq 0.25)$ and almost no depolarization $(\approx 3 \%)$. This is consistent with the properties of the layers measured by the aircraft (Table 2). The depolarization values measured at $355 \mathrm{~nm}$ by the aircraft $(2 \%)$ are slightly smaller than the expected $\delta_{355}(2.5 \%)$ for a $\delta_{532}$ of $3 \%$, but the CALIOP volume depolarization values in this region are nevertheless smaller than all the CALIOP data reported in Tables $3 \mathrm{a}$ and $3 \mathrm{~b}$. The good correspondence between the aerosol properties of the CALIOP layers and the airborne lidar layers for a time scale of 1 day, is the first necessary condition if one aims at using the CALIOP observations further upwind in order to unsderstand the sources of the aerosol layers seen by the aircraft.

The analysis of Table $3 \mathrm{a}$ and $3 \mathrm{~b}$ focused on layers with backscatter values, $\beta_{532} \geq 210^{-3} \mathrm{~km}^{-1} \mathrm{sr}^{-1}(R \geq 2)$ i.e. with an intensity strong enough to be able to discuss the optical properties. The position of the layers must also be considered in the interpretation of this table as three Asian sources are known to dominate the aerosol composition at this time of the year: the desert dust advected from the Gobi and Taklamakan desert (Duce et al., 1980) in the latitude band $40^{\circ} \mathrm{N}-50^{\circ} \mathrm{N}$, the industrial emissions from the Heilongjiang region further east in the same latitude band, and the forest fires from the Lake Baikal region in the latitude band $50^{\circ} \mathrm{N}-55^{\circ} \mathrm{N}$. Therefore four main results can be underlined from this table:

- Looking at the strongest aerosol layers prior to April 8 , two kinds of aerosol properties can be found in the $45^{\circ}-52^{\circ} \mathrm{N}$ where several sources influence the aerosol properties (layers colored in gold in table $3 \mathrm{a}$ ): one with low pseudo color ratio (near 0.3$)$ and low $\delta_{532}(0-7 \%)$ for longitude $<125^{\circ} \mathrm{E}$ (text in black Table $3 \mathrm{a}$ ), and the other one with larger pseudo color ratio $(0.5$ to 1$)$ and larger $\delta_{532}(10-14 \%)$ for longitude $>135^{\circ} \mathrm{E}$ (i.e. near the Pacific coast, text in red in Table 3a). 
Table 4. Aerosol layer characteristics from the CALIPSO observations for the backward FLEXPART model run initialized at $68.5^{\circ} \mathrm{N}-69^{\circ} \mathrm{N}$, $3.5-5 \mathrm{~km}$ (Layer I).

\begin{tabular}{ccccccccccc}
\hline Date & $\begin{array}{c}\text { Time } \\
\text { UT }\end{array}$ & $\begin{array}{c}\text { CALIOP } \\
\text { Start } \\
\text { Lat./Lon }\end{array}$ & $\begin{array}{c}\text { End } \\
\text { Lat./Lon }\end{array}$ & $\begin{array}{c}\text { Flexpart } \\
\text { layer } \\
\text { alt, } \mathrm{km}\end{array}$ & $\begin{array}{c}\text { Mean } \\
\beta_{532} \\
\mathrm{~km}^{-1} \mathrm{sr}^{-1}\end{array}$ & $\begin{array}{c}\text { Pseudo } \\
\text { Color } \\
\text { ratio }\end{array}$ & $\begin{array}{c}\text { Pseudo } \\
\text { Mean } \\
\delta_{532}\end{array}$ & $\begin{array}{c}\text { Aerosol } \\
\text { Color } \\
\text { ratio }\end{array}$ & $\begin{array}{c}\text { FCF } \\
\text { rio }\end{array}$ \\
\hline $08 / 4$ & $01: 27$ & $52.05 / 13.36$ & $55.86 / 15.24$ & $1.7-5.4$ & $27 \pm 1.10^{-4}$ & $0.44 \pm 0.28$ & $0.08 \pm 0.06$ & $0.7 \pm 0.54$ & D \\
$09 / 4$ & $02: 11$ & $58.45 / 5.91$ & $62.72 / 8.87$ & $3.1-5.3$ & $17 \pm 4.10^{-4}$ & $0.23 \pm 0.21$ & $0.05 \pm 0.06$ & $0.47 \pm 0.91$ & C.C. \\
$10 / 4$ & $02: 54$ & $66.26 / 1.21$ & $70.21 / 5.97$ & $2.5-5.3$ & $16 \pm 4.10^{-4}$ & $0.23 \pm 0.18$ & $0.04 \pm 0.03$ & $0.51 \pm 0.97$ & P.D. \\
$10 / 4$ & $10: 16$ & $64.76 / 23.94$ & $64.88 / 23.82$ & $2.6-5.0$ & $39 \pm 13.10^{-4}$ & $0.40 \pm 0.50$ & $0.10 \pm 0.14$ & $0.53 \pm 1.13$ & P.D. \\
$11 / 4$ & $01: 58$ & $65.94 / 14.79$ & $68.41 / 17.49$ & $2.7-5.2$ & $16 \pm 3.10^{-4}$ & $0.10 \pm 0.17$ & $0.03 \pm 0.02$ & $0.18 \pm 0.71$ & C.C. \\
\hline
\end{tabular}

D: Dust. C.C.: Clean Continental. P.D.: Polluted Dust. S: Smoke.

- Near the Siberian fire sources $\left(55^{\circ}-60^{\circ} \mathrm{N}, 90^{\circ}-120^{\circ} \mathrm{E}\right)$, $\beta_{532} \leq 210^{-3} \mathrm{~km}^{-1} \mathrm{sr}^{-1}(R \approx 1.5)$ with a 0.3 pseudo color ratio and a weak $\delta_{532}(4-7 \%)$, i.e. with probably small aerosol which did not have time to grow as when transported through a very humid frontal system (layers colored in light brown in Table 3a)

- At latitude larger than $60^{\circ} \mathrm{N}$ (i.e. in the Arctic region), one can distinguish two regions: (i) the layers detected above Alaska with a color ratio of $0.3-0.4$ and some depolarization (9-10\%) although smaller than the values for lower latitudes near the Asian Pacific coast, (ii) the layers in the Eurasian Arctic with a variable color ratio $0.3-0.5$ and lower $\delta_{532}(2-8 \%)$

- As the air masses are transported from Asia to Scandinavia across the Arctic, there is a general tendency for decreasing $\beta_{532}$ from 3 to $1.510^{-3} \mathrm{~km}^{-1} \mathrm{sr}^{-1}$ (i.e. $R$ from 3 to 1.7) and fewer air masses with elevated pseudo color ratio or pseudo depolarization ratio. Notice also that there is not a very clear dependency of the optical properties with altitude in the detected layers considered in this study.

The CALIOP aerosol feature classification flag (FCF) derived from the operational products is also reported in Tables $3 \mathrm{a}, 3 \mathrm{~b}, 4$. This classication is mainly based on the depolarization and color ratio, the attenuated backscatter amplitude and layer altitude (Liu et al., 2004). This can be compared with our own interpretation of the aerosol source influencing the layers. One can see that the agreement is certainly good for the layers where we suspect the desert dust to be mixed with the polluted emissions from north-east Asia (gold). The main discrepancies are for the layers in the Siberian fire region where the CALIOP operational products assumed mainly dust sources, while our analysis suggest a dominant influence from boreal fires. The CALIOP analysis is mainly related to the weak increase of $\delta_{532}$, but it does not take into account the likely small size of the aerosols and the large number of fires in this region in April 2008. Also the CALIOP FCF tends to define layers encountered after several days of transport as clean continental, while our analysis shows a connection between the Asian polluted sources and the area above Scandinavia. This is probably a limit of the CALIOP FCF for making a precise continental source attribution after several days of transport which resulted on a large decrease of the attenuated backscatter.

One plausible hypothesis for explaining the largest $\delta_{532}$ and elevated pseudo color ratio for the CALIPSO layers in the area $\left(45^{\circ}-52^{\circ} \mathrm{N}, 135^{\circ}-140^{\circ} \mathrm{E}\right)$ is that the southernmost CALIPSO tracks near the coast are influenced both by the desert dust and north-east Asian emissions. The higher color ratio is consistent with larger aerosol particles resulting from a remaining influence of dust but also from the likely growth of the pollution aerosol in the frontal system responsible for the northward transport which develops near the Pacific coast on 5-7 April (Fig. 10). Airborne in-situ aerosol measurements of the ratio of ultrafine $(3-70 \mathrm{~nm})$ to fine particles (70$200 \mathrm{~nm}$ ) over Siberia in Spring 2006 by Paris et al. (2009) have shown, for similar meteorological conditions, that this ratio decreases for polluted air masses from north-east Asia.

Further west, where northward motion is less efficient, the Siberian boreal fires gradually become the main aerosol source (Warneke et al., 2009), explaining a significant decrease in both the pseudo color ratio and $\delta_{532}$, as expected for biomass burning aerosol according to the work of Cattrall et al. (2005). This means that the three sources have influenced the aerosol composition over Scandinavia and that the depolarization ratio should provide a way to separate the biomass burning plume from the north-east Asian emissions because of the remaining influence of the desert emissions in the $40^{\circ} \mathrm{N}-50^{\circ} \mathrm{N}$ latitude band.

Above $60^{\circ} \mathrm{N}$, the Alaskan layers can be considered as aged Asian layers being transported across the Pacific to Alaska as reported in the analysis of the 2008 spring period transport pathways described in Fuelberg et al. (2009), but also from the modeling work of Fisher et al. (2009) 
showing the widespread influence Asian CO sources including Alaska. This can explain the values of the depolarization ratio which are intermediate between the low values above Scandinavia and the large values above North Eastern Asia. Considering all the layers in the Arctic region the slight decrease of the color ratio which is concomitant with the lower $\beta_{532}$, would indicate the gradual removal of the largest aerosol particles due either to mixing of the different aerosol type being present above Asia or to the wet removal of the largest hydrophilic aerosol particles during the transport processes.

Finally the CALIPSO analysis of the aerosol layer properties above Asia would now suggest that the source attribution of the different layers observed by the lidar in the Asian plume could be the following: remaining influence of north-east Asian emissions mixed with dust for the layer II-A at $69.7^{\circ} \mathrm{N}$ and more predominantly Siberian fire influence for the layer II-B further north. The combined use of FLEXPART together with analysis of the CALIPSO data allows more robust conclusions to made regarding the different sources influencing observed aerosol layers north of Scandinavia after more than 5 days of transport from source regions.

When it is compared with the analysis of the Asian plume, the results of Table 4 show smaller changes of the aerosol properties during the transport from central Europe. The pseudo color ratio and the depolarization ratio are less than 0.4 and $8 \%$, respectively, above the sources in central Europe. These values are intermediate between the ones observed for the two types of Asian layers discussed previously . This is not so surprising since industrial European emissions dominate the aerosol composition where larger aerosols from the accumulation modes are less numerous. Episodic transport from the Sahara in the exported air mass from Europe is possible (Hamonou et al., 1999), Fuelberg et al. (2009) showed that 10-day trajectories reaching $70^{\circ} \mathrm{N}$ and originating from Sahara were almost negligible during the 2008 spring season compared to the potential export of Asian dust.

\section{Conclusions}

In this paper we have analysed airborne and spaceborne lidar aerosol data related to the transport of two different sources into the Arctic during April 2008: a European plume and an Asian plume. In the case studied here both plumes exhibit elevated $\mathrm{CO}$ concentrations indicating a significant fraction of either biomass burning or anthropogenic pollution sources. Although the aerosol optical depths are similar for both layers, their optical properties are quite different. We used mainly the pseudo volume depolarization at $355 \mathrm{~nm}$ and pseudo color ratio between 1064 and 532 to distinguish both layers because they are more stable quantities when looking at relative variations of the optical properties of layers with low aerosol optical depths $(<4 \%)$, as encountered in this study. These ratios are also more comparable to CALIOP version 2.1 aerosol layer properties than other parameters, e.g. the aerosol color ratio or the aerosol depolarization ratio.

The European plume (layer I) contains smaller particles with very low $355 \mathrm{~nm}$ depolarization $(1.6 \pm 0.3 \%)$ and low pseudo color ratios $(0.009 \pm 0.002 \%)$. The Asian plume is characterized by larger particles and some $355 \mathrm{~nm}$ depolarization $(2.1 \pm 0.3 \%)$ in one layer (layer II-A, i.e. with a larger fraction of dust particles). Measurements of the aerosol size spectrum along the flight have also shown that the variability of the pseudo color ratio can be related to the actual change of the aerosol size distribution even for layers where the optical depth is small and consequently an increase of the pseudo color ratio error. This also gives confidence in the possibility of using the same kind of information in the CALIOP aerosol data products (pseudo color ratio between 1064 and $532 \mathrm{~nm}$, pseudo volume depolarization at $532 \mathrm{~nm}$ ). in the analysis of aerosol layers of moderate intensity when transported across the Arctic, even considering the expected larger error bar (30-100\%) in the CALIOP data compared to the errors in the aircraft observations.

The comparison of the CALIOP data with the airborne data over northern Scandinavia showed that the pseudo color ratio and the volume depolarization ratio are in a reasonable agreement considering the error bar on the CALIOP data and the fact that time and spatial coincidences of the measurements are only possible in a 1-day time frame and a $500 \mathrm{~km}$ by $800 \mathrm{~km}$ longitude/latitude band. Nevertheless, these results show that CALIOP aerosol data products can be used to study the evolution of layer aerosol properties over a period of several days.

To understand the variability of the airborne observations, the transport of the air masses was investigated using specific FLEXPART simulations including calculation of the PBL air fraction originating from three different mid-latitude source regions: Asia, North America and Europe. Results from the transport model were combined with the CALIPSO overpasses to link our observations with CALIOP results obtained near the remote sources (Asia, Central Europe), consequently improving the identification of the aerosol sources responsible for the aerosol layers observed by the aircraft after a transport time of more than 4-5 days.

For example, above Asia, the CALIOP data indeed suggest more $532 \mathrm{~nm}$ pseudo depolarization (up to $15 \%$ ) and the largest pseudo color ratio $(>0.5)$ for north-east Asian emissions where there is a mixture of Asian pollution and dust, while low depolarization together with smaller and quasi constant pseudo color ratio $(\approx 0.3)$ are observed for the Siberian biomass burning emissions. A similar difference is visible between layer II-A and II-B observed by the aircraft above Scandinavia. It means that distinct signatures of the three aerosol sources (biomass burning, industrial emissions and desert) are still visible after being transported across the Arctic with the influence of the mixture of Asian pollution and dust being stronger for layer II-A. Of course the analysis 
remains qualitative considering the difficulty in quantifying the different processes modifying the aerosol properties. This would require specific Lagrangian modeling of the aerosol evolution which is not within the scope of this paper. Notice however that it would have been difficult to discuss the remaining influence of different aerosol sources using the trajectory model alone which is less able to distinguish source regions after several days of transport.

The analysis of the time evolution of the aerosol optical properties revealed by CALIOP between the source regions and northern Scandinavia after 4-5 days of transport over the Arctic, suggests a gradual decrease in the 532-nm attenuated backscatter, the volume depolarization ratio and the pseudo color ratio which can be related to the removal of the largest particles in the accumulation mode (e.g. by wet removal in the frontal system responsible for the northward transport). A mixture of the three Asian aerosol sources also contributes to reductions in the volume depolarization and pseudo color ratio towards their lowest values, respectively $2 \%$ and 0.1 .

The analysis of the European plume showed aerosol optical properties intermediate between the two Asian sources with pseudo color ratios never exceeding 0.4 and moderate volume depolarization ratios being always less than $8 \%$, i.e. less aerosol from the accumulation mode. In common with the Asian plume, the time evolution of the European plume suggests the removal of the largest particles, thus explaining the aerosol spectrum observed by the aircraft in this case.

Finally, one conclusion of this paper is that CALIOP aerosol products have indeed a large error bar when dealing with quantities like the pseudo color and volume depolarization ratio, but are however valuable tools making source attribution of aerosol layers when used in conjunction with a Lagrangian transport model. It works also for aerosol layers of moderate intensity far away from the major aerosol sources. The comparison with the CALIOP operational FCF aerosol classification indeed show a good agreement for dust source identification, but also differences with our analysis where we include more information (air mass transport, positions of forest fires back in time, pseudo color ratio) than the CALIOP methodology based on the depolarization ratio, the local surface type and the attenuated backscatter intensity.

\section{Appendix A}

\section{Backscatter lidar parameter definition}

In this appendix, we are aiming at defining the parameters derived from a backscatter lidar and more precisely from the knowledged of the total volume backscatter coefficient at wavelength $\lambda$ which can be split into the molecular (Rayleigh) and aerosol contribution:

$\beta_{\lambda}(z)=\beta_{\lambda, m}(z)+\beta_{\lambda, a}(z)$ where the subscripts $m$ and a specify, respectively, molecular, and aerosol contributions to the scattering process. A backscatter lidar measures the range corrected lidar signal, $P_{\lambda}(z)$, at range $z$, which can be related to $\beta_{\lambda}(z)$ by the following equation:

$P_{\lambda}(z)=K_{\lambda}\left(\beta_{\lambda, m}(z)+\beta_{\lambda, a}(z)\right) \cdot T_{\lambda, m}(z)^{2} \cdot T_{\lambda, a}(z)^{2}$.

where $K_{\lambda}$ the range independent calibration coefficient of the lidar system and $T^{2}$ is the two-way transmittance due to any scattering (or absorbing) species along the optical path between the scattering volume at range $z$ and the lidar. The two-way transmittance for any constituent, $x$, is

$T_{x}(z)^{2}=\exp \left(-2 \tau_{x}(z)\right)=\exp \left(-2 \int_{0}^{z} \sigma_{x}\left(z^{\prime}\right) d z^{\prime}\right)$.

where $\tau_{x}(z)$ specifies the optical depth and $\sigma_{x}(z)$ is the volume extinction coefficient. Molecular contribution can be estimated with a good accuracy using either a density model or meteorological radiosonde data available for the measurement area. When the aerosol contribution is negligible at a range $z_{0}$ near the lidar (i.e. where $\tau_{x}\left(z_{0}\right)$ is small), one can determinate the lidar system constant $K$ from the value of $P\left(z_{0}\right)$. If we divide $P(z)$ by this value and normalize to the Rayleigh contribution, we obtain the attenuated backscatter ratio, $R(z)$, given by:

$R(z)=\frac{P(z)}{K \beta_{\lambda, m}(z) \cdot \exp \left(-2 \tau_{\lambda, m}(z)\right)} \approx 1+\frac{\beta_{\lambda, a}(z)}{\beta_{\lambda, m}(z)}$

if $\tau_{\lambda, a}$ remains small (this is the case for this study).

When a linear polarized laser beam is emitted, depolarization related to backscattering in the atmosphere can be measured by a receiving lidar system with an optical selection of the parallel- and cross-polarized signal.The backscatter ratios, $R$, for perpendicular- and parallel-polarized light are defined as

$R_{\perp}(z)=1+\frac{\beta_{\perp, a}(z)}{\beta_{\perp, m}(z)} \quad R_{\|}(z)=1+\frac{\beta_{\|, a}(z)}{\beta_{\|, m}(z)}$

and the ratio of the aerosol cross- to parallel-polarized backscatter coefficient is called the linear volume depolarization ratio, $\delta_{a}$, given by:

$\delta_{a}(z)=\frac{\beta_{\perp, a}(z)}{\beta_{\|, a}(z)}=\frac{R_{\perp}(z)-1}{R_{\|}(z)-1} . \delta_{m} \quad \delta_{m}=\frac{\beta_{\perp, m}}{\beta_{\|, m}}$

The Rayleigh depolarization and its wavelength dependency can be found in Bucholtz (1995), e.g. $\delta_{m}=0.015$ at $355 \mathrm{~nm}$. Since this ratio depends critically on the absolute accuracy of the backscatter ratio retrieval, the ratio of the total crossto the total parallel-polarized backscatter coefficient is also used and called hereafter the pseudo depolarization ratio $\delta$ given by:

$\delta(z)=\frac{\beta_{\perp}(z)}{\beta_{\|}(z)}=\frac{R_{\perp}(z)}{R_{\|}(z)}=\delta_{a}(z)\left(1-\frac{1}{R_{\|}(z)}\right)+\frac{\delta_{m}}{R_{\|}(z)}$. 
The pseudo depolarization ratio, $\delta$, tends to $\delta_{m}$ only in a clean region where $R_{\|}$tends to 1 . Notice that in a thick aerosol layer where the aerosol depolarization is less than the molecular depolarization, $\delta$ could tend to zero. The pseudo depolarization ratio $\delta$ has the advantage of being less unstable when the aerosol layer is weak and it is also less dependent on instrumental parameters (Cairo et al., 1999). According to Freudenthaler et al. (2009), the aerosol depolarization ratio $\delta_{a}$ has only a small spectral variation between $532 \mathrm{~nm}$ and $355 \mathrm{~nm}$ for dust particles, i.e. for aerosol with a large depolarization value. For example, they found that $\delta_{a}$ is 0.3 at $532 \mathrm{~nm}$ and 0.28 at $355 \mathrm{~nm}$ for saharan dust plume. However the wavelength dependency of $\delta$ is related also to the spectral change of the backscatter ratio. This will have to taken into account when comparing $\delta_{355}$ and $\delta_{532}$. For example, the layer II-A discussed in this paper has a $\delta_{a}$ value of the order of $3 \%$, while $R_{355}=1.5$ and $R_{532}=2$. Assuming no spectral variation of $\delta_{a}$ implies a $\delta$ variation from $2 \%$ to $2.2 \%$ when switching the wavelength from 355 to $532 \mathrm{~nm}$.

The ratio of aerosol backscatter at $1064 \mathrm{~nm}$ to the aerosol backscatter at $532 \mathrm{~nm}$ is called the color ratio, CR, given by

$\mathrm{CR}(z)=\frac{\beta_{a, 1.06}(z)}{\beta_{a, 0.53}(z)}=\frac{R_{1.06}(z)-1}{R_{0.53}(z)-1} \cdot \frac{1}{16}$

where $1 / 16$ is the ratio of the $1064-\mathrm{nm}$ to the $532-\mathrm{nm}$ molecular backscatter. The ratio of total backscatter at $532 \mathrm{~nm}$ and the total backscatter at $1064 \mathrm{~nm}$ can also be calculated for the same reasons which lead us to use the pseudo depolarization ratio. This new ratio, called hereafter the pseudo color ratio, is related to $\mathrm{CR}$ by the following equation:

$\mathrm{CR}^{*}(z)=\frac{\beta_{1.06}(z)}{\beta_{0.53}(z)}=\mathrm{CR}(z)\left(1-\frac{1}{R_{0.53}(z)}\right)+\frac{1}{16 R_{0.53}(z)}(\mathrm{A} 9)$

The pseudo ratio $\mathrm{CR}^{*}$ can be as small as $1 / 16$, when the aerosol contribution is small (i.e. $R$ much less than 1.5). The CR ratio provides a better representation of the size influence on the aerosol optical properties variation with the wavelength (O'Neill et al., 2003) as it is more directly related to the Angström coefficient which is the standard parameter for discussing this spectral dependency and which is defined as:

$k=-\frac{d \ln \tau_{a}}{d \ln \lambda}$.

Since $k$ depends on aerosol extinction and not on aerosol backscatter coefficients, the relation between $k$ and CR depends on the ratio of these two coefficient, also called the lidar ratio $B$. The ratio CR is related to $k$ by the equation:

$\mathrm{CR}(z)=\frac{B_{0.5, a}(z)}{B_{1.06, a}(z)} \cdot 2^{-k}$.

When the fine mode aerosol contribution decreases, $k$ varies from values around 2 to values near 0 and CR increases from values near 0.5 to values near 1 , assuming that the corresponding $\frac{B_{0.53, a}}{B_{1.06, a}}$ changes goes from 2 to 1 according to Cattrall et al. (2005). The change of the pseudo ratio $\mathrm{CR}^{*}$ goes in the same direction, but with a smaller amplitude as $R$ decreases. For example, $\mathrm{CR}^{*}$ does not exceeds 0.5 even for the largest CR values when $R$ remains around 2. Notice also that for small optical depths and small values of the coarse mode fraction, the model calculation of (O'Neill et al., 2003) suggests that $k$ can be larger than 2 and therefore the smallest $\mathrm{CR}^{*}$ may become less than 0.2 even when $R$ does not become too small (i.e. above 1.5).

Acknowledgements. The UMS SAFIRE is acknowledged for supporting the ATR-42 aircraft deployment and for providing the aircraft meteorological data. The POLARCAT-FRANCE project was supported by ANR, CNES, CNRS/INSU and IPEV. F. Blouzon and D. Bruneau are acknowledged for their contribution to the lidar operation during flights, and Ariane Bazureau for her work on FLEXPART modeling. John Burkhart from NILU is acknowledged for providing FLEXPART products on the POLARCAT web site. The NASA data center in charge of the CALIPSO data is greatfully acknowledged for providing the CALIOP lidar data.

Edited by: A. Stohl

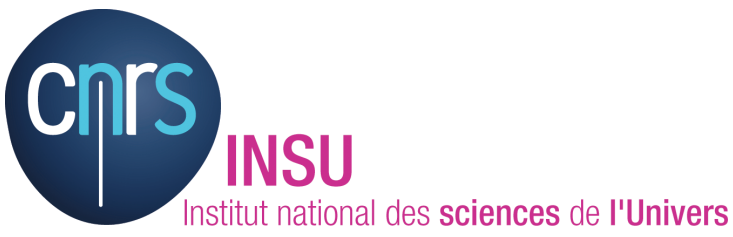

The publication of this article is financed by CNRS-INSU.

\section{References}

Atlas, E. L., Ridley, B. A., and Cantrell, C.: The Tropospheric Ozone Production about the Spring Equinox (TOPSE) Experiment: Introduction, J. Geophys. Res., 108(D4), 8353, doi:10.1029/2002JD003172, 2003.

Bethan, S., Vaughan, G., and Reid, S.: A comparison of ozone and thermal tropopause heights and the impact of tropopause definition on quantifying the ozone content of the troposphere, Q. J. Roy. Meteorol. Soc., 122, 929-944, 1996.

Browell, E. V., Hair, J., Butler, C., Grant, W., DeYoung, R., Fenn, M., Brackett, V., Clayton, M., Brasseur, L., Harper, D., Ridley, B., Klonecki, A., Hess, P., Emmons, L., Tie, X., Atlas, E., Cantrell, C., Wimmers, A., Blake, D., Coffey, M., Hannigan, J., Dibb, J., Talbot, R., Flocke, F., Weinheimer, A., Fried, A., Wert, B., Snow, J., and Lefer, B.: Ozone, aerosol, potential vorticity, and trace gas trends observed at high-latitudes over North America from February to May 2000, J. Geophys. Res., 108(D4), 8369, doi:10.1029/2001JD001390, 2003.

Bucholtz, A.: Rayleigh-scattering calculations for the terrestrial atmosphere, Appl. Opt., 34, 2765-2773, doi:10.1364/AO. 34.002765, http://ao.osa.org/abstract.cfm?URI=ao-34-15-2765, 1995.

Cairo, F., Donfrancesco, G. D., Adriani, A., Pulvirenti, L., and Fierli, F.: Comparison of Various Linear Depolarization Parameters Measured by Lidar, Appl. Opt., 38, 4425-4432, http: //ao.osa.org/abstract.cfm?URI=ao-38-21-4425, 1999. 
Capes, G., Johnson, G., G.McFiggans, Williams, P., Haywood, J., and Coe, H.: Aging of biomass burning aerosols over West Africa: Aircraft measurements of chemical composition, microphysical properties, and emission ratios, J. Geophys. Res., 113, D00C15, doi:10.1029/2008JD009845, 2008.

Cattrall, C., Reagan, J., Thome, K., and Dubovik, O.: Variability of aerosol and spectral lidar and backscatter and extinction ratios of key aerosol types derived from selected Aerosol Robotic Network locations, J. Geophys. Res., 110, D10S11, doi: 10.1029/2004JD005124, 2005.

Coheur, P.-F., Clarisse, L., Turquety, S., Hurtmans, D., and Clerbaux, C.: IASI measurements of reactive trace species in biomass burning plumes, Atmos. Chem. Phys., 9, 5655-5667, doi:10.5194/acp-9-5655-2009, 2009.

Duce, R. A., Unni, C. K., Ray, B. J., Prospero, J. M., and Merrill, J. T.: Long-Range Atmospheric Transport of Soil Dust from Asia to the Tropical North Pacific: Temporal Variability, Science, 209, 1522-1524, http://www.jstor.org/stable/1684974, 1980.

Eguchi, K., Uno, I., Yumimoto, K., Takemura, T., Shimizu, A., Sugimoto, N., and Liu, Z.: Trans-pacific dust transport: integrated analysis of NASA/CALIPSO and a global aerosol transport model, Atmos. Chem. Phys., 9, 3137-3145, doi:10.5194/acp-93137-2009, 2009.

Engvall, A., Krejci, R., Ström, J., Minikin, A., Treffeisen, R., Stohl, A., and Herber, A.: In-situ airborne observations of the microphysical properties of the Arctic tropospheric aerosol during late spring and summer, Tellus B, 60 (3), 392-404, doi:10.1111/j.1600-0889.2008.00348.x, 2008.

Fehsenfeld, F. C., Ancellet, G., Bates, T. S., Goldstein, A. H., Hardesty, R. M., Honrath, R., Law, K. S., Lewis, A. C., Leaitch, R., McKeen, S., Meagher, J., Parrish, D. D., Pszenny, A. A. P., Russell, P. B., Schlager, H., Seinfeld, J., Talbot, R., and Zbinden, R.: International Consortium for Atmospheric Research on Transport and Transformation (ICARTT): North America to Europe Overview of the 2004 summer field study, J. Geophys. Res., 111, D23S01, doi:10.1029/2006JD007829, 2006.

, Flamant, C. and Pelon, J.: Atmospheric boundary layer structure over the Méditerranée during a Tramontane event, Q. J. Roy. Met. Soc., 122, 1741-1778,1996.

Fisher, J. A., Jacob, D. J., Purdy, M. T., Kopacz, M., Le Sager, P., Carouge, C., Holmes, C. D., Yantosca, R. M., Batchelor, R. L., Strong, K., Diskin, G. S., Fuelberg, H. E., Holloway, J. S., Hyer, E. J., McMillan, W. W., Warner, J., Streets, D. G., Zhang, Q., Wang, Y., and Wu, S.: Source attribution and interannual variability of Arctic pollution in spring constrained by aircraft (ARCTAS, ARCPAC) and satellite (AIRS) observations of carbon monoxide, Atmos. Chem. Phys. Discuss., 9, 19035-19080, doi:10.5194/acpd-9-19035-2009, 2009.

Freudenthaler, V., Esselborn, M., Wiegner, M., Heese, B., Tesche, M., Ansmann, A., Müller, D., Althausen, D., Wirth, M., Fix, A., Ehret, G., Knippertz, P., Toledano, C., Gasteiger, J., Garhammer, M., and Seefeldner, M.: Depolarization ratio profiling at several wavelengths in pure Saharan dust during SAMUM 2006, Tellus, 61B, 165-179, doi:10.1111/j.1600-0889.2008.00396.x, http://dx.doi.org/10.1111/j.1600-0889.2008.00396.x, 2009.

Fuelberg, H. E., Harrigan, D. L., and Sessions, W.: A meteorological overview of the ARCTAS 2008 mission, Atmos. Chem. Phys. Discuss., 9, 18417-18478, doi:10.5194/acpd-9-184172009, 2009.
Garrett, T. and Zhao, C.: Increased Arctic cloud longwave emissivity associated with pollution from mid-latitudes, Nature, 440, 787-789, 2006.

Gobbi, G. P., Barnaba, F., Van Dingenen, R., Putaud, J. P., Mircea, M., and Facchini, M. C.: Lidar and in situ observations of continental and Saharan aerosol: closure analysis of particles optical and physical properties, Atmos. Chem. Phys., 3, 2161-2172, doi:10.5194/acp-3-2161-2003, 2003.

Hamonou, E., Chazette, P., Balis, D., Dulac, F., Schneider, X., Galani, E., Ancellet, G., and Papayannis, A.: Characterization of the vertical structure of Saharan dust export to the mediterranean basin, J. Geophys. Res., 104, 22257-22270, 1999.

Hess, M., P. Koepke, and I. Schult: Optical properties of aerosols and clouds: The software package OPAC, B. Am. Meteor. Soc., 79, 831-844, 1998.

Hostetler C. A., Z. Liu, J. Reagan, M. Vaugahn, D. Winker, M. Osborn, W. Hunt, K. A. Powell, C. Trepte: Cloud-Aerosol Lidar Infrared Pathfinder Satellite Observations CALIOP Algorithm Theoretical Basis Document, NASA-CNES Document No: PCSCI-201, 66 pp., available at http://www-calipso.larc.nasa, 2006.

Jacob, D. J., Crawford, J. H., Maring, H., Clarke, A. D., Dibb, J. E., Ferrare, R. A., Hostetler, C. A., Russell, P. B., Singh, H. B., Thompson, A. M., Shaw, G. E., McCauley, E., Pederson, J. R., and Fisher, J. A.: The ARCTAS aircraft mission: design and execution, Atmos. Chem. Phys. Discuss., 9, 17073-17123, doi:10.5194/acpd-9-17073-2009, 2009.

Kampe, T. and Sokolik, I.: Remote sensing retrievals of fine mode aerosol optical depth and impacts on its correlation with CO from biomass burning, Geophys. Res. Lett., 34, L12806, doi:10.1029/ 2007GL029805, 2007.

Law, K. and Stohl, A.: Arctic Air Pollution: Origins and Impacts, Science, 315(5818), 1537-1540, doi:10.1126/science.1137695, 2007.

Liu, Z., Omar, A. H., Hu, Y., Vaughan, M. A., and Winker, D. M.: CALIOP Algorithm Theoretical Basis Document Part 3: Scene Classification Algorithms, 2004.

Liu, Z., Vaughan, M., Winker, D., Kittaka, C., Getzewich, B., Kuehn, R., Omar, A., Powell, K., Trepte, C., and Hostetlerd, C.: The CALIPSO Lidar Cloud and Aerosol Discrimination: Version 2 Algorithm and Initial Assessment of Performance, J. Atmos. Ocean. Tech., 26, 1198-1213, doi:10.1175/2009JTECHA1229. $1,2009$.

Liu Z., Vaughan, M. A., Winker, D. M., Hostetler, C. A., Poole, L. R., Hlavka, D., Hart, W., and McGill, M.: Use of probability distribution functions for discriminating between cloud and aerosol in lidar backscatter data, J. Geophys. Res., 109, 1502, doi:10.1029/2004JD004732, 2004

Mattis, I., Ansmann, A., Müller, D., Wandinger, U., and Althausen, D.: Multiyear aerosol observations with dual-wavelength Raman lidar in the framework of EARLINET, J. Geophys. Res., 109, D13203, doi:10.1029/2004JD004600, 2004.

Methven, J., Arnold, S. R., Stohl, A., Avery, M., Law, K., Lewis, A., Parrish, D., Reeves, C., Schlager, H., Atlas, E., Blake, D., and Rappenglück, B.: Establishing Lagrangian connections between observations within air masses crossing the Atlantic during the ICARTT experiment, J. Geophys. Res., 111, D23S62, doi:10.1029/2006JD007 540, 2006.

Nedelec, P., Cammas, J.-P., Thouret, V., Athier, G., Cousin, J.-M., Legrand, C., Abonnel, C., Lecoeur, F., Cayez, G., and Marizy, 
C.: An improved infrared carbon monoxide analyser for routine measurements aboard commercial Airbus aircraft: technical validation and first scientific results of the MOZAIC III programme, Atmos. Chem. Phys., 3, 1551-1564, doi:10.5194/acp-3-15512003, 2003.

Omar, A., Winker, D., Kittaka, C., Vaughan, M., Liu, Z., Hu, Y., Trepte, C., Rogers, R., Ferrare, R., Lee, K., Kuehn, R., and Hostetler, C.: The CALIPSO Automated Aerosol Classification and Lidar Ratio Selection Algorithm, J. Atmos. Ocean. Tech., 26, 1994-2014, doi:10.1175/2009JTECHA1231.1, 2009.

OŃeill, N., Eck, T., Smirnov, A., Holben, B., and Thulasiraman, S.: Spectral discrimination of coarse and fine mode optical depth, J. Geophys. Res., 108, 4559, doi:10.1029/2002JD002975, 2003.

Paris, J.-D., Arshinov, M. Y., Ciais, P., Belan, B. D., and Nédélec, P.: Large-scale aircraft observations of ultra-fine and fine particle concentrations in the remote Siberian troposphere: New particle formation studies, Atmos. Environ., 43, 1302-1309, doi: 10.1016/j.atmosenv.2008.11.032, 2009.

Pelon, J., Flamant, C., Chazette, P., Léon,J. F., Tanré, D., Sicard, M., and Satheesh, S. K.: Characterization of aerosol spatial distribution and optical properties over the Indian Ocean from airborne lidar and radiometry during INDOEX'99, J. Geophys. Res., 107(D19), 8029, doi:doi:10.1029/2001JD000402, 2002.

Pueschel, R. and Kinne, S.: Physical and radiative properties of Arctic atmospheric aerosols, Science of The Total Environment, 160-161, 811-824, doi:10.1016/0048-9697(95)04414-V, 1995.

Quinn, P. K., Bates, T. S., Baum, E., Doubleday, N., Fiore, A. M., Flanner, M., Fridlind, A., Garrett, T. J., Koch, D., Menon, S., Shindell, D., Stohl, A., and Warren, S. G.: Short-lived pollutants in the Arctic: their climate impact and possible mitigation strategies, Atmos. Chem. Phys., 8, 1723-1735, doi:10.5194/acp8-1723-2008, 2008.

Radlach, M., Behrendt, A., and Wulfmeyer, V.: Scanning rotational Raman lidar at $355 \mathrm{~nm}$ for the measurement of tropospheric temperature fields, Atmos. Chem. Phys., 8, 159-169, doi:10.5194/acp-8-159-2008, 2008.

Rahn, K. A.: Relative importances of North America and Eurasia as sources of arctic aerosol, Atmospheric Environment, 15, 14471455, doi:10.1016/0004-6981(81)90351-6, 1981.

Scheuer, E., Talbot, R. W., Dibb, J. E., Seid, G. K., DeBell, L., and Lefer, B.: Seasonal distributions of fine aerosol sulfate in the North American Arctic basin during TOPSE, J. Geophys. Res., 108(D4), 8370, doi:10.1029/2001JD001364, 2003.

Seibert, P. and Frank, A.: Source-receptor matrix calculation with a Lagrangian particle dispersion model in backward mode, Atmos. Chem. Phys., 4, 51-63, doi:10.5194/acp-4-51-2004, 2004.

Sellegri, K., Hanke, M., Umann, B., Arnold, F., and Kulmala, M.: Measurements of organic gases during aerosol formation events in the boreal forest atmosphere during QUEST, Atmos. Chem. Phys., 5, 373-384, doi:10.5194/acp-5-373-2005, 2005.

Shindell, D. T., Chin, M., Dentener, F., Doherty, R. M., Faluvegi, G., Fiore, A. M., Hess, P., Koch, D. M., MacKenzie, I. A., Sanderson, M. G., Schultz, M. G., Schulz, M., Stevenson, D. S., Teich, H., Textor, C., Wild, O., Bergmann, D. J., Bey, I., Bian, H., Cuvelier, C., Duncan, B. N., Folberth, G., Horowitz, L. W., Jonson, J., Kaminski, J. W., Marmer, E., Park, R., Pringle, K. J., Schroeder, S., Szopa, S., Takemura, T., Zeng, G., Keating, T. J., and Zuber, A.: A multi-model assessment of pollution transport to the Arctic, Atmos. Chem. Phys., 8, 5353-5372, doi:10.5194/acp-8-5353-2008, 2008.

Stohl, A., Hittenberger, M., and Wotawa, G.: Validation of the Lagrangian particle dispersion model FLEXPART against large scale tracer experiment data, Atmos. Environ., 32, 4245-4264, 1998.

Stohl, A., Eckhardt, S., Forster, C., James, P., Spichtinger, N., and Seibert, P.: A replacement for simple back trajectory calculations in the interpretation of atmospheric trace substance measurements, Atmos. Environ., 36, 4635-4648, 2002.

Stohl, A., Cooper, O. R., Damoah, R., Fehsenfeld, F. C., Forster, C., Hsie, E. Y., Hübler, G., Parrish, D. D., and Trainer, M.: Forecasting for a Lagrangian aircraft campaign, Atmos. Environ., 4, 2405-2433, 2004.

Stohl, A., Berg, T., Burkhart, J. F., Fjae'raa, A. M., Forster, C., Herber, A., Hov, Ø., Lunder, C., McMillan, W. W., Oltmans, S., Shiobara, M., Simpson, D., Solberg, S., Stebel, K., Ström, J., Tørseth, K., Treffeisen, R., Virkkunen, K., and Yttri, K. E.: Arctic smoke - record high air pollution levels in the European Arctic due to agricultural fires in Eastern Europe in spring 2006, Atmos. Chem. Phys., 7, 511-534, doi:10.5194/acp-7-511-2007, 2007a.

Stohl, A., Forster, C., Huntrieser, H., Mannstein, H., McMillan, W. W., Petzold, A., Schlager, H., and Weinzierl, B.: Aircraft measurements over Europe of an air pollution plume from Southeast Asia - aerosol and chemical characterization, Atmos. Chem. Phys., 7, 913-937, doi:10.5194/acp-7-913-2007, 2007b.

Streets, D. and Waldhoff, S.: Present and future emissions of air pollutants in China:: SO2, NOx, and CO, Atmos. Environ., 34, 363-374, doi:10.1016/S1352-2310(99)00167-3, 2000.

Sugimoto, N. and Lee, C. H.: Characteristics of dust aerosols inferred from lidar depolarization measurements at two wavelengths, Appl. Opt., 45, 7468-7474, http://ao.osa.org/abstract. cfm?URI=ao-45-28-7468, 2006.

Warneke, C., Bahreini, R., Brioude, J., Brock, C., de Gouw, J., Fahey, D., Froyd, K., Holloway, J., Middlebrook, A., Miller, L., Montzka, S., Murphy, D., Peischl, J., Ryerson, T., Schwarz, J., Spackman, J., and Veres, P.: Biomass burning in Siberia and Kazakhstan as an important source for haze over the Alaskan Arctic in April 2008, Geophys. Res. Lett., 36, L02813, doi: 10.1029/2008GL036194, 2009.

Weber, R., Orsini, D., Wang, B., Scheuer, E., Talbot, R., Dibb, J., Seid, G., DeBell, L., Mauldin, R., Kosciuch, E., Cantrell, C., and Eisele, F.: Investigations into free tropospheric new particle formation in the central Canadian arctic during the winter/spring transition as part of TOPSE, J. Geophys. Res., 108(D4), 8357, doi:10.1029/2002JD002239, 2003.

Winker, D. M., Vaughan, M., Omar, A., Hu, Y., Powell, K., Liu, Z., Hunt, W., and Young, S.: Overview of the CALIPSO Mission and CALIOP Data Processing Algorithms, J. Atmos. Oceanic Technol., 26, 2310-2323, doi:10.1175/2008JTECHA1221.1, 2009. 